\title{
Observed Cross-Shelf Flow Induced by Mesoscale Eddies in the Northern South China Sea
}

\author{
Qiang WANG, LiLi Zeng, JiAn Li, Ju Chen, YunKai He, Jinglong YaO, \\ DONGXIAO WANG, AND WEIDONG ZHOU
}

State Key Laboratory of Tropical Oceanography, South China Sea Institute of Oceanology, Chinese Academy of Sciences, Guangzhou, China

(Manuscript received 13 September 2017, in final form 16 May 2018)

\begin{abstract}
Cross-shelf flow induced by mesoscale eddies has been investigated in the northern South China Sea (NSCS) using velocity observations from Long Ranger ADCP moorings. Mesoscale eddies influenced the three mooring stations during almost all the observation period. Four quadrants have been defined with the mooring location as the origin, and it is found that warm (cold) mesoscale eddies induce onshore (offshore) movement in the eastern two quadrants and offshore (onshore) movement in the western two quadrants. When an eddy propagates past a mooring station, net cross-shelf flow at the mooring station can be induced by asymmetry in the horizontal and vertical structure of the eddy and by its evolution. As an eddy propagates westward, its shape changes continually and the vertical modes also transform from high to lower modes, which contributes to the net cross-shelf flow. Based on the quasigeostrophic potential vorticity equation, it is confirmed that the net cross-shelf flow is mainly induced by the eddy evolution and suppressed by nonlinear effect. Because of dispersion characteristics of the mesoscale eddy, barotropic mode will restructure at the baroclinic mode area after separating from the baroclinic mode, which will be enhanced by topography slope.
\end{abstract}

\section{Introduction}

The South China Sea (SCS) is the largest semiclosed marginal sea in the tropics, connecting to the northwest Pacific through the Luzon Strait. The northern SCS (NSCS) has a broad shelf and slope, with the Dongsha Islands located about $200 \mathrm{~km}$ offshore over the upper continental slope (Fig. 1). There is a seasonally reversing western boundary current driven by the monsoon and Kuroshio intrusion in the upper-layer ocean on the NSCS shelf, making up the northern part of the basin-scale circulation, which is cyclonic in winter and anticyclonic in summer (Hu et al. 2000; Qu 2000; Wang et al. 2013a,b).

There is significant cross-shelf flow in the NSCS, with an annual average value of $9.4 \mathrm{~Sv}$ (onshore; $1 \mathrm{~Sv} \equiv$ $10^{6} \mathrm{~m}^{3} \mathrm{~s}^{-1}$ ) across the 500-m isobath (Huang et al. 2017), which has important dynamic implications for the continent currents (Wang et al. 2010; Wang et al. 2014). The along-isobaths density gradient is the main driver and the wind-stress curl is secondary (Wang et al. 2015a; Huang et al. 2017). An interesting phenomenon is the

Corresponding author: Dr. Dongxiao Wang, dxwang@scsio.ac.cn dipole in cross-shelf flow on the two sides of the Dongsha Islands produced by the topography and baroclinic density field (Wang et al. 2013a; Huang et al. 2016). In winter, the offshore movement to the west side of the Dongsha Islands is relatively strong and forms a current in the middle layer that separates under joint effect of baroclinicity and relief (JEBAR; Wang et al. 2013a).

Mesoscale eddies play an important role in dynamical oceanography across a range of scales (Wunsch 1999; Qiu and Chen 2005) and are key transporters of oceanic material (Dong et al. 2014; Zhang et al. 2014, 2016). The large-scale current is generally much weaker than timevarying signals (Qiu and Chen 2005), and the transport induced by mesoscale eddies contributes to the closing of the global heat budget (Stammer 1998; Wunsch 1999; Qiu and Chen 2005; Dong et al. 2014). The continental shelf is often occupied by mesoscale eddies, and eddyinduced cross-shelf flow is an important conveyor for exchange between the open sea and continent (Peliz et al. 2004; Mizobata et al. 2006).

In the SCS, many eddies are evident in hydrographic datasets (Xu et al. 1982; Chu et al. 1998; Li et al. 1998; Zhang et al. 2016) and satellite sea level anomaly data 


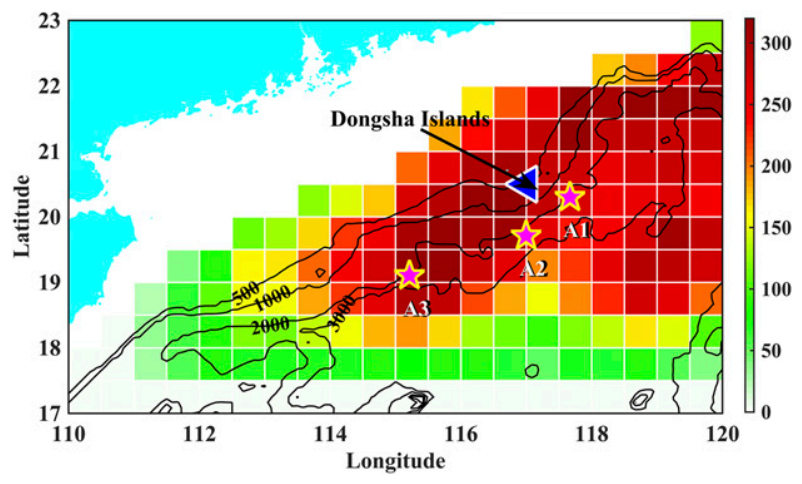

FIG. 1. The NSCS. Bathymetry is shown by black contours. The magenta and yellow stars indicate the mooring stations (A1-A3). Color shading indicates the accumulated eddy-influence days over each grid square during the observation period (18 Sep 2014 to 20 Jun 2016). Light blue indicates land.

(Li et al. 2002; Su et al. 2002; Yuan et al. 2007; Chow et al. 2008; Wang et al. 2008; Chu et al. 2014). The formation of mesoscale eddies in the SCS occurs mainly through shedding from the Kuroshio intrusion ( $\mathrm{Li}$ et al. 1998; Wang et al. 2000; Yang et al. 2000; Li et al. 2002; Su et al. 2002; Jia and Liu 2004; Yuan et al. 2006) and the action of the local wind-stress jet (Yang and Liu 2003; Wang et al. 2008; Nof et al. 2011). Model output and satellite altimeter data indicate a mean number of $32.9 \pm 2.4$ eddies each year with mean radius and lifetime of $132 \mathrm{~km}$ and 8.8 weeks, respectively (Wang et al. 2003; Xiu et al. 2010; Chen et al. 2011). The NSCS shelf is an energetic region for eddy activity (Wang et al. 2003; Nan et al. 2011; Zu et al. 2013; Yang et al. 2016), and these mesoscale eddies are the main contributors to intraseasonal variability in the NSCS (Zhuang et al. 2010).

Chen et al. (2012) estimated basin-scale eddy heat and salt transports in the SCS and their seasonal modulation. They found that the transports were horizontally variable due to asymmetric distributions of temperature and salinity anomalies. Three paths of large poleward (equatorward) eddy heat (salt) transport were located to the east of Vietnam in summer, west of the Luzon Islands in winter, and west of the Luzon Strait. The complicated topography and small spatial scale mean that the commonly used methods for estimating eddy transport based on the diffusion coefficient are not very effective on the shelf; in situ data are also relatively scarce. Thus, our understanding of the eddy-induced cross-shelf flow in the NSCS shelf is still limited.

Long-period mooring observations were conducted on the NSCS shelf (Fig. 1) to give a direct estimate of the eddy-induced cross-shelf flow. The NSCS has been divided into $0.5 \times 0.5$ grid squares, and the number of eddy-influence days on each grid square (i.e., the accumulated number of days for which more than half of a specific grid square is occupied by an eddy) has been calculated during the observation period (Fig. 1). In the NSCS, there are two zones of high eddy activity: to the west of the Luzon strait and in the middle of the NSCS continental shelf where the mooring stations are located. In this paper, we analyze the cross-shelf flow induced by mesoscale eddies on the NSCS shelf using these mooring observations, in order to improve our understanding of mesoscale eddies.

The remainder of this paper is organized as follows. Section 2 describes the data and methods. In section 3, features of the eddy-induced cross-shelf flow are discussed for eddies in different quadrants relative to the mooring positions using an ensemble of eddies, together with the asymmetry of the cross-shelf flow. A discussion is given in section 4. Finally, conclusions are given in section 5 .

\section{Data and methods}

\section{a. Altimetry and mooring data}

The merged sea surface height anomalies (SSHAs) from TOPEX/Poseidon, Jason-1, and European Research Satellite (ERS-1 and ERS-2), provided by the French Archiving, Validation, and Interpretation of Satellite Oceanographic Data (AVISO) project, are used to identify and track eddies. The product is available as a daily cycle with $1 / 4^{\circ}$ resolution.

Three moorings (A1-A3) are located on the NSCS shelf (Fig. 1), and the observation period is from 20 September 2014 to 20 June 2016, except for mooring A1, which was only maintained up to 15 September 2015. The sampling time intervals were $1 \mathrm{~h}$ or $30 \mathrm{~min}$, and the vertical resolutions were $8 \mathrm{~m}$. There are upwardand downward-looking ADCPs of $75 \mathrm{~K}$ at A1, which are generally deployed at $\sim 380 \mathrm{~m}$ and $410 \mathrm{~m}$ respectively. At station A2, a 75-K upward-looking ADCP is deployed at $\sim 420 \mathrm{~m}$, and a $150-\mathrm{K}$ upward-looking ADCP is deployed at $\sim 700 \mathrm{~m}$. Two upward-looking $75-\mathrm{K}$ ADCPs are deployed at $340 \mathrm{~m}$ and $840 \mathrm{~m}$, respectively, at station A3. Detailed information on the moorings is listed in Table 1.

Each ADCP is equipped with pressure gauge, and the collected velocities have been interpolated onto $50 \mathrm{~m} \sim 850 \mathrm{~m}$ with a resolution of $8 \mathrm{~m}$, using a linear interpolation method (outside the observation depth range is invalid data). Then the velocity has been averaged over $24 \mathrm{~h}$ (daily), and a bandpass filter (10-130 days) used to remove high-frequency signals and background mean currents. The velocity is projected onto the direction orthogonal to the topography, 
TABLE 1. Moorings, instruments, and deployment periods.

\begin{tabular}{|c|c|c|c|c|c|c|}
\hline $\begin{array}{l}\text { Station } \\
\text { name }\end{array}$ & $\begin{array}{c}\text { Water } \\
\text { depth }(\mathrm{m})\end{array}$ & Location & $\begin{array}{l}\text { Measurement } \\
\text { period }\end{array}$ & $\begin{array}{l}\text { Instrument } \\
\text { type }\end{array}$ & $\begin{array}{l}\text { Measurement } \\
\text { range }(\mathrm{m})\end{array}$ & $\begin{array}{c}\text { Sampling } \\
\text { frequency } \\
\text { (h) }\end{array}$ \\
\hline \multirow[t]{2}{*}{ A1 } & \multirow[t]{2}{*}{2224} & \multirow[t]{2}{*}{$20.30^{\circ} \mathrm{N}, 117.67^{\circ} \mathrm{E}$} & \multirow[t]{2}{*}{18 Sep 2014-15 Sep 2015} & Upward 75-K ADCP & $50-378$ & 1 \\
\hline & & & & Downward 75-K ADCP & $410-890$ & 1 \\
\hline \multirow[t]{2}{*}{ A2 } & \multirow[t]{2}{*}{2392} & \multirow[t]{2}{*}{$19.71^{\circ} \mathrm{N}, 116.99^{\circ} \mathrm{E}$} & \multirow[t]{2}{*}{20 Sep 2014-20 Jun 2016} & Upward 75-K ADCP & $50-418$ & 1 \\
\hline & & & & Upward 150-K ADCP & $458-690$ & 0.5 \\
\hline \multirow[t]{2}{*}{ A3 } & \multirow[t]{2}{*}{2060} & \multirow[t]{2}{*}{$19.01^{\circ} \mathrm{N}, 115.21^{\circ} \mathrm{E}$} & \multirow[t]{2}{*}{20 Sep 2014-20 Jun 2016} & Upward 75-K ADCP & $50-338$ & 1 \\
\hline & & & & Upward 75-K ADCP & $370-834$ & 1 \\
\hline
\end{tabular}

and positive values indicate the onshore direction. A five-point smoothing filter has been applied to the topography when calculating its gradient to remove the large aspect ratio. The bathymetry is prescribed by ETOPO2 (Marks and Smith 2006).

\section{b. Mesoscale eddy detection method}

To identify the mesoscale eddies, an eddy detection scheme based on the geometry of the velocity vectors has been used (Nencioli et al. 2010). This scheme has been successfully applied in eddy analysis and has low rates of both commission and omission errors (Dong et al. 2012; Liu et al. 2012). The eddy center, shape, and tracks can be obtained with this scheme.

\section{c. Definition of the period during which a mesoscale eddy influences a mooring station}

To estimate the cross-shelf flow induced by a mesoscale eddy, the period over which an eddy contributes to the local flow must be defined. In this paper, this period is defined as follows. First, we detected the outermost closed contour of a mesoscale eddy. Starting from the value at the eddy center with an interval of $0.1 \mathrm{~cm}$, we detect whether there is a closed contour around the eddy center until it fails, and then the last value is defined as the outermost closed contour. Thus, the time that the mooring station lies within the contour is defined as the mesoscale eddy influence period. When the mooring station is located between two mesoscale eddies and it is difficult to distinguish which one is dominant, the mooring is influenced by both until one eddy propagates away.

\section{Cross-shelf flow induced by a mesoscale eddy}

Cross-shelf flows from the three moorings are shown in Fig. 2, and the mesoscale eddy influence periods are marked on the top of the Fig. 2 along with the eddy identity (ID number) for convenience. Eddies occur throughout almost the whole observation period. Large positive or negative cross-shelf flows occur associated with mesoscale eddies, and both barotropic and baroclinic features are present in different cases.

\section{a. Features of cross-shelf flow in different quadrants from an ensemble of eddies}

To estimate the eddy-induced cross-shelf flow, four quadrants have been defined with the mooring location as the origin (Fig. 3). The relative locations of the detected mesoscale eddies that affect the associated mooring are plotted on the four quadrants. Each quadrant contains many eddies, and there is a clear pattern of eddy distribution in all three moorings along a belt from quadrant 1 to quadrant 3 . This belt reveals the southwestward propagation path along the continental shelf that has been reported in many studies (Wang et al. 2003; Xiu et al. 2010; Chen et al. 2011; Nan et al. 2011). There are also many eddies in quadrant 4 , which indicates the region northwest of the Philippines, where the orographic wind jets and Kuroshio intrusion are the main contributors to eddy genesis (Jia and Liu 2004; Wang et al. 2008). After genesis, an eddy may be trapped

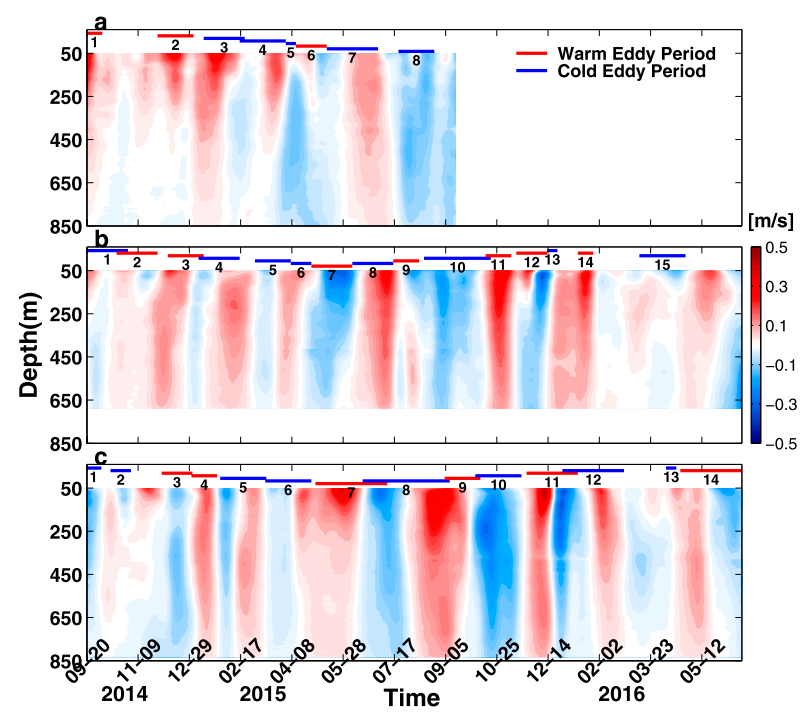

FIG. 2. Observations of cross-shelf flow (positive denotes onshore) from station (a) A1, (b) A2, and (c) A3. The red (blue) lines indicate the periods when a warm (cold) mesoscale eddy influenced the moorings. The numbers on the lines are the mesoscale eddy ID numbers used in the text. 

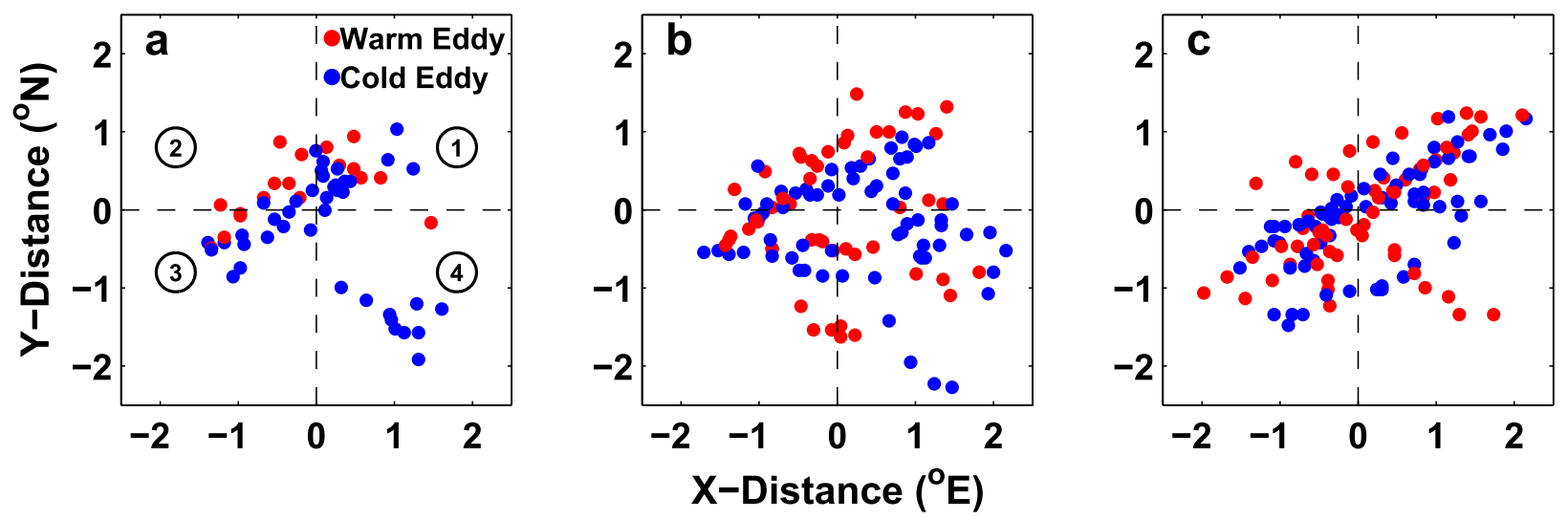

FIG. 3. Mesoscale eddy locations relative to each mooring station during the observation period for (a) station A1, (b) station A2, and (c) station A3. The mesoscale eddy locations were sampled at a frequency of 5 days. The numbers in (a) indicate the different quadrants.

locally, propagate westward, or ascend onto the continental shelf (Yang and Liu 2003; Nof et al. 2011; Wang et al. 2015b).

The ensemble-mean cross-shelf flow induced by eddies in different quadrants has been estimated. The cross-shelf flow of mooring A1 is shown in Fig. 4. A warm eddy can induce onshore movement when it lies in the first and fourth quadrants, and offshore movement in the other two quadrants. This is consistent with the horizontal structure of a warm mesoscale eddy. The cross-shelf flow of $O\left(10^{-1}\right) \mathrm{m} \mathrm{s}^{-1}$ is mainly in the upper $400 \mathrm{~m}$, and the vertical profile is significantly baroclinic. In the first quadrant, the vertical structure corresponds to the first baroclinic mode, and the second baroclinic mode can be found in the second and third quadrants. Cold eddies have the opposite cross-shelf flow in quadrants one to three. However, the vertical structure of the cross-shelf flow induced by a cold eddy is mainly barotropic, which may imply that the cold eddy has deeper anomalies than the warm case in this zone, especially in the first quadrant. In the fourth quadrant, the cold-eddyinduced cross-shelf flow is positive, which is not consistent with our understanding that the left side of the cold eddy should give offshore movement due to the cyclonic rotation. This cross-shelf flow in the fourth quadrant is mainly induced by eddy 3 (Fig. 2a), the so-called Luzon Cold Eddy (LCE), which lies northwest of the Philippines. Although its center is located in the fourth quadrant and far away from mooring A1, its long axis tilts toward the northwest and its edge touches the continental shelf. The mooring A1 is on the right-hand side of its long axis, so positive cross-shelf flow is observed.

Mooring A2 is southwest of A1 and the direction of eddy-induced cross-shelf flow is similar to that of A1 (Fig. 5). The cold-eddy-induced cross-shelf flow in the fourth quadrant is negative, as there are more cases than for mooring A1. However, the vertical structure is quite different from that of mooring A1. For a warm eddy, the vertical profile is significantly barotropic except in the third quadrant, where the first baroclinic mode is evident. Although more eddies are involved in estimating the cross-shelf flow in A2, the comparison between these two moorings before September 2015 (Figs. 2a,b) still shows that A2 is more obviously barotropic than A1. The mesoscale eddies propagate westward, and the same eddy will be involved in estimates of the mean cross-shelf flow at both moorings A1 and A2. The changes in the vertical structure may indicate that the vertical features of a mesoscale eddy can evolve and change considerably as it propagates westward. The transformation of the vertical mode as the eddy evolves has also been reported in many studies (McWilliams and Flierl 1979; Welsh and Inoue 2000; Sutyrin et al. 2003).

At mooring station A3 (Fig. 6), the direction of the cross-shelf flow is the same as in A2 in each quadrant and the barotropic mode is more significant, which confirms that the eddy behaves more barotropically as it propagates westward on the NSCS shelf. The number of eddy days is smallest in the second quadrant, for both warm and cold eddies. This is because most of the eddies around mooring A3 propagate from the east (Wang et al. 2003; Chen et al. 2011) and it is easier for them to propagate downslope (Smith 1986).

The above discussion shows that warm eddies can induce positive cross-shelf flow in the first and fourth quadrants, but negative in the second and third quadrants, with the opposite occurring for cold eddies. Cold eddies are more barotropic than warm eddies around mooring A1. The high baroclinic modes transform to lower modes as the eddies propagate westward. 


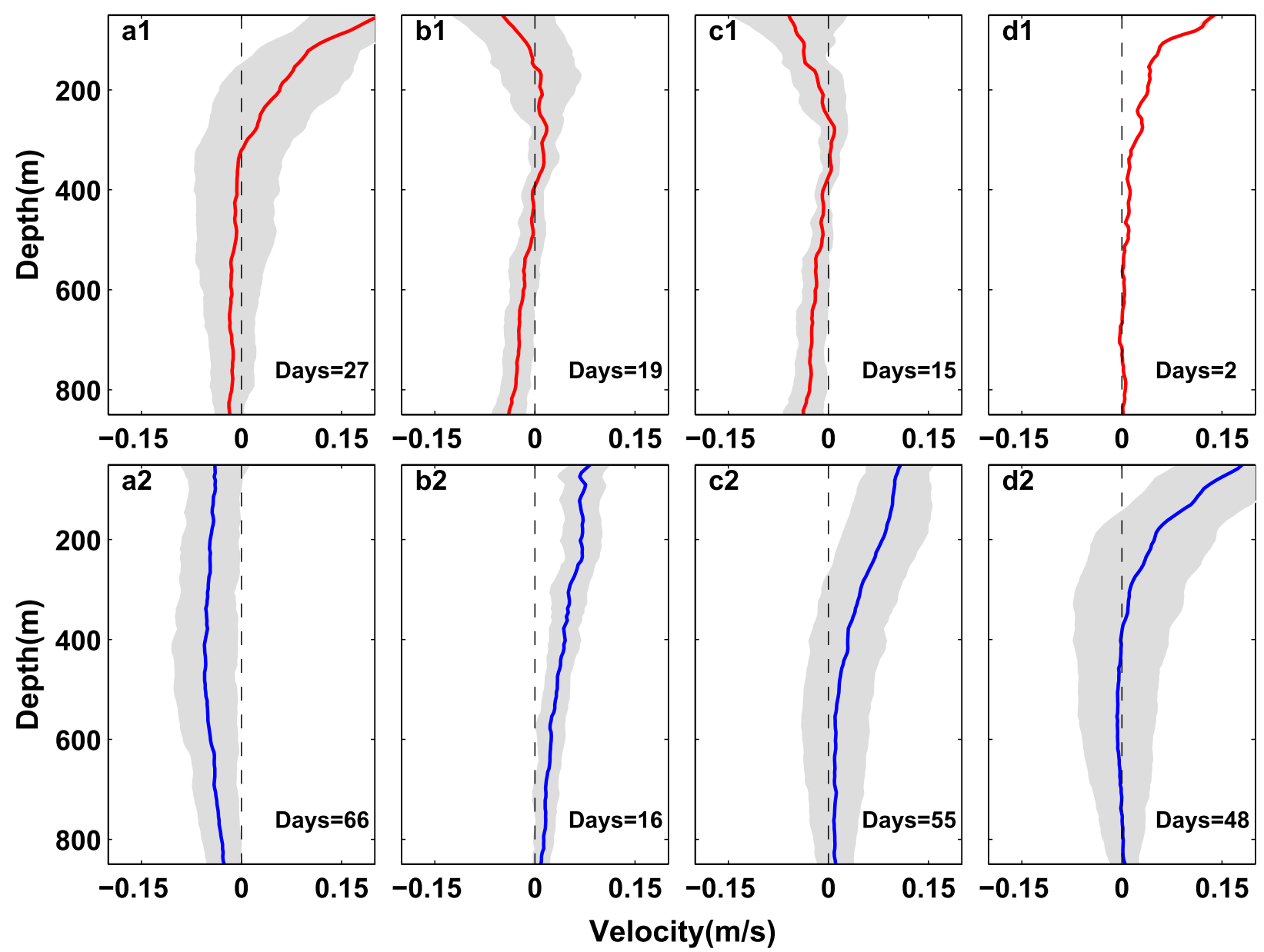

FIG. 4. Mean eddy-induced cross-shelf flow profile (positive indicates onshore) in different quadrants from station A1. The upper (lower) panels are for warm (cold) mesoscale eddies from the (a1),(a2) first quadrant; (b1),(b2) second quadrant; (c1),(c2) third quadrant; and (d1),(d2) fourth quadrant. Shading indicates one standard deviation of the cross-shelf flow. The mean cross-shelf flow profile is the average over the number of days given in the lower right corner of each panel.

\section{b. Asymmetric cross-shelf flow induced by mesoscale eddies}

The cross-shelf flow induced by eddies that propagate across different quadrants is now analyzed. Each eddy has been divided into two periods: one when its center is in the first or fourth quadrants (east of the mooring station) and the other when its center is in the second or third quadrants (west of the mooring station).

Only one warm eddy was detected at mooring station A1 (Fig. 7a1), and the cross-shelf flow is similar to that in the above discussion (Fig. 4). The warm eddy induced positive (negative) upper cross-shelf flow when it was east (west) of mooring A1. High baroclinic modes dominate the vertical structure (Fig. 7b1). Two cold eddies have been detected that induced positive (negative) cross-shelf flow when west (east) of mooring A1. The vertical structure is clearly barotropic. The most significant feature is the asymmetric cross-shelf flow induced by the mesoscale eddy as it propagates past the mooring station. Five warm and four cold eddies have been detected at mooring A2 (Fig. 7a2), with barotropic modes dominating all the cross-shelf flow vertical structures (Figs. 7b2,c2). Asymmetric cross-shelf flow is found for both the warm and cold eddies, but is more obvious for the cold eddies. At mooring A3, there are also five warm and four cold eddies, and the associated cross-shelf flow is very similar to that of mooring A2 (Figs. 7a3,b3,c3). The asymmetric cross-shelf flow is also more obvious when a cold eddy propagates past $\mathrm{A} 3$. Where the cross-shelf flow is asymmetric, net cross-shelf transport can be induced by mesoscale eddies and contributes to the interaction between the continent and the deep open basin.

The asymmetric cross-shelf flow may be induced by the evolution and asymmetric shape of mesoscale eddies. The averaged SSHA in the two periods for each eddy is obtained, and the outermost contour of SSHA is 

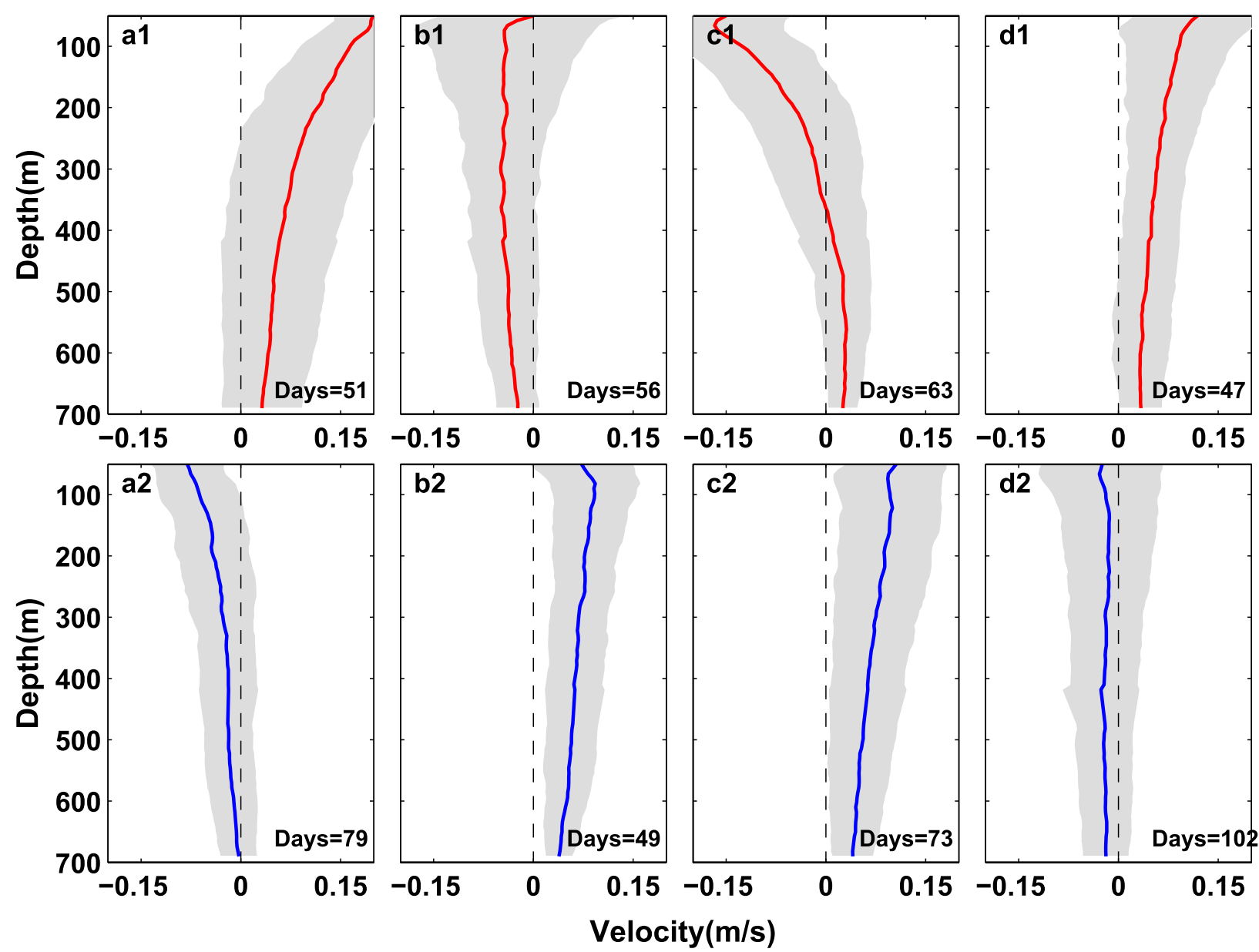

FIG. 5. As in Fig. 4, but for station A2.

defined as the eddy shape. We then calculated the scaled vorticity $\left[\xi=\left(\partial_{x} v-\partial_{y} u\right) / f\right.$, where $f$ is the local planetary vorticity and $(u, v)$ are the sea surface meridional and zonal geostrophic velocity from the SSHAs] of each averaged eddy based on the geostrophic velocity in the two periods separately, and the averaged vorticity and its relative changes $\left[\left(\xi_{w-} \xi_{e}\right) / \bar{\xi}\right.$; i.e., the value west of the mooring minus that east of the mooring] between the two periods are shown in Fig. 8 . Also shown in the figure are the shape and net cross-shelf flow of each eddy integrated between 50 and $300 \mathrm{~m}$.

Figure 8 shows that the shape of the mesoscale eddy changes as it propagates westward and that net crossshelf flow is induced. The larger the shape change, the larger the net cross-shelf flow in many cases, such as eddies 10 and 14 at mooring A2. The mesoscale eddy satisfies quasigeostrophic (QG) balance, meaning that the horizontal velocity structure depends to a large extent on the shape defined by the SSHA. Therefore, a different change in eddy shape as it propagates westward can induce different cross-shelf flow at the mooring. The net cross-shelf flow at mooring A3 is much smaller than at mooring A2, and the shape change is also smaller. This implies that the mesoscale eddy evolves more as it passes A2 than A3, which may be due to the complex topography (Yang et al. 2016) and background currents induced by the Kuroshio intrusion (Nan et al. 2011; Zu et al. 2013) on the eastern segment of the NSCS shelf. Vorticity changes also indicate eddy evolution, and there is a good relationship between the vorticity changes and net cross-shelf flow. However, there is no significant relationship between the sign of cross-shelf flow and the vorticity changes. Both the shape and vorticity change are different aspects of mesoscale eddy evolution, and the asymmetric eddy structure can induce significant net cross-shelf flow as it evolves.

\section{c. Features of individual mesoscale eddies}

Two individual mesoscale eddies that propagate from mooring A1 to A3 have been selected to analyze the details of cross-shelf flow induced by an eddy. Case 1 is a warm eddy (eddy ID: 6 in A1, 7 in both A2 and A3) with track shown in Fig. 9a. It moved from shallow water 


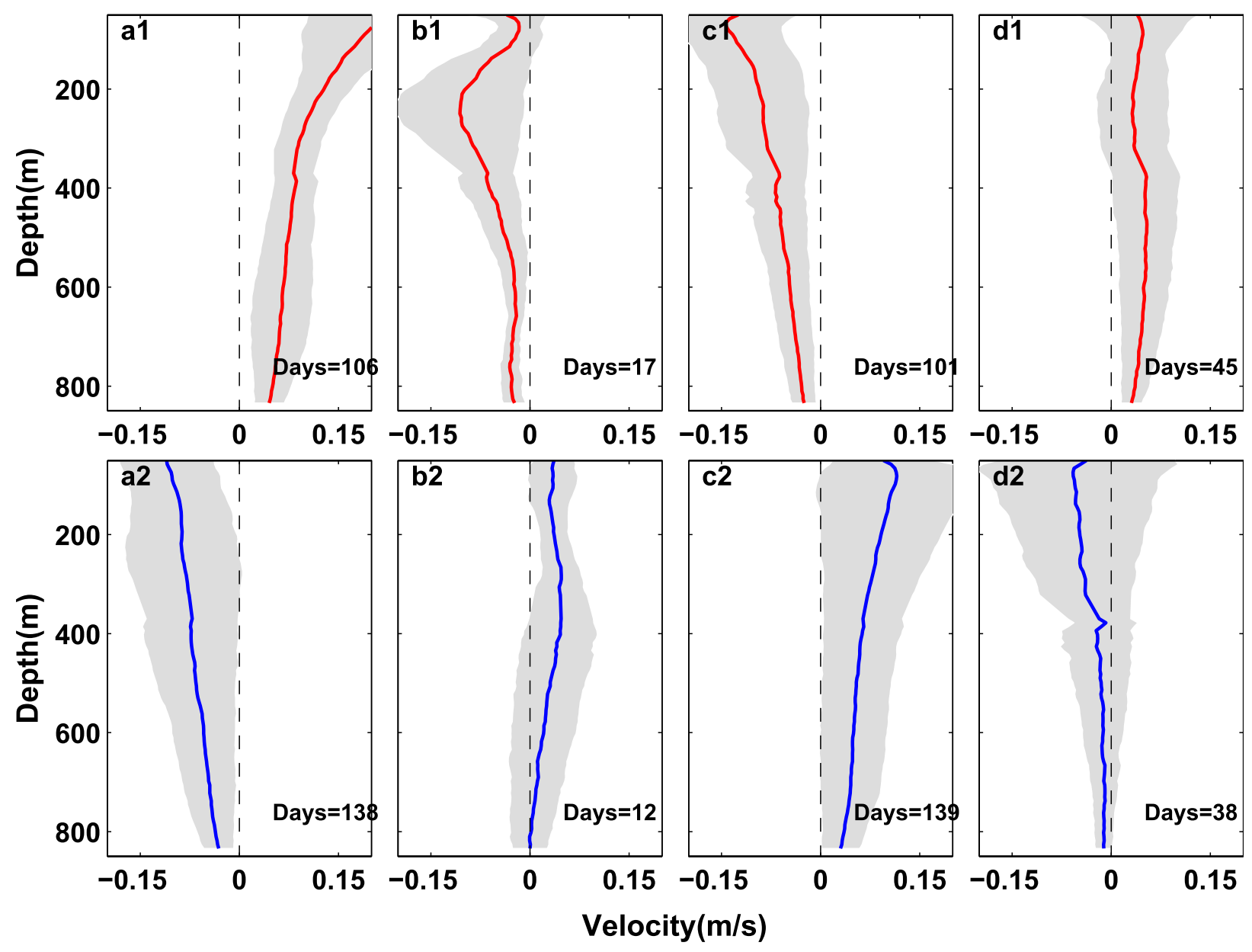

FIG. 6. As in Fig. 4, but for station A3.

northeast of mooring A1 and propagated southwestward downslope, influencing all three mooring stations. The sign of the cross-shelf flow changed after its center had propagated closest to the mooring station (Figs. 9b,c), which is consistent with the above discussion that a warm eddy induces positive (negative) cross-shelf flow in the first and fourth (second and third) quadrants. The vertical structure (Fig. 9c) is significantly baroclinic at mooring A1, and the vertical structure gradually became barotropic at moorings $\mathrm{A} 2$ and $\mathrm{A} 3$. The warm eddy center is at some distance from the mooring $\mathrm{A} 1$ as it propagated toward A2. The vertical structure at the edge of this warm eddy may be shallower than at its center, thereby inducing the baroclinic feature. The center approaches more closely to mooring stations A2 and A3, especially A3. The edge of this warm eddy must reach the two moorings first, followed by its center. However, there is no significant barotropic mode at mooring A2 for the positive cross-shelf flow and no significant baroclinic mode at mooring A3. This indicates that the vertical mode of this warm eddy has indeed transformed. Figure $9 \mathrm{c}$ shows that the baroclinic mode of the positive cross-shelf flow at mooring A1 did not transform to a significant barotropic mode at A2, but did at mooring A3, which means that the vertical mode transformation took a long time. Different vertical mode features can be found for the cross-shelf flow profile of this warm eddy center east and west of the mooring stations, demonstrating the asymmetric distribution of the warm eddy's vertical modes.

Observations of this warm eddy are also divided into two periods as above, propagating toward and away from the mooring station. Empirical orthogonal function (EOF) decomposition has been applied to each period (Fig. 10). The first two EOFs contribute more than $90 \%$ of the variance. The EOFs show more clearly the eddy's asymmetry and vertical mode evolution. Higher baroclinic modes are present in Fig. 10a than in Fig. 10b, and the transformation from baroclinic to barotropic can be seen more easily by comparing Fig. 10a1 with Fig. 10a3 (or Fig. 10b1 with Fig. 10b3).

Case 2 is a cold eddy (eddy ID: 7 in A1, 8 in both A2 and A3) with a path as shown in Fig. 11a. The vertical 

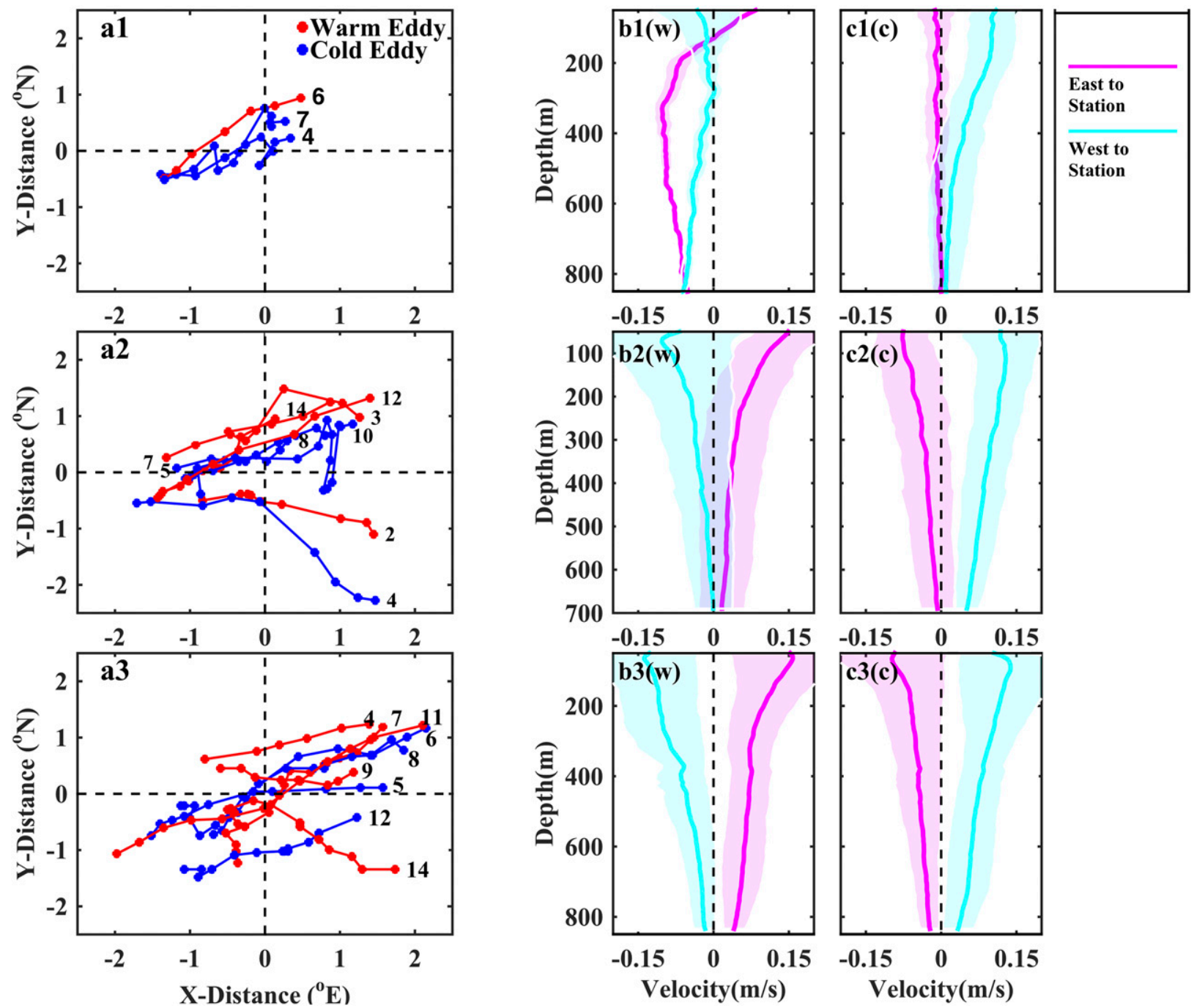

FIG. 7. (left) Paths of mesoscale eddies and corresponding cross-shelf flow for (center) warm eddies and (right) cold eddies from station (top) A1, (middle) A2, and (bottom) A3. East (west) to station: cross-shelf flow induced by a mesoscale eddy when its center is east (west) of the station. Shading indicates one standard deviation of the cross-shelf flow.

structure of this cold eddy is obviously barotropic, but the asymmetry in the vertical structure can also be found in all three moorings. The evolution of SSHA (Fig. 11a) shows that the shape of this cold eddy changed considerably as it propagated, resulting in large net cross-shelf flow (Fig. 8). The EOF decomposition of this cold eddy (Fig. 12) demonstrates the two points discussed above, that is, the asymmetric structure in both the horizontal and vertical, and transformation of the vertical modes during westward propagation.

\section{Discussion}

Significant cross-shelf flow can be induced by mesoscale eddy based on the above discussion; however, there are still some limitations of the single point observation. Some other process may be difficult to be distinguished, such as topography-trapped waves, which can also trigger a cross-shelf flow. It is not easy to discuss the dynamics that control these cross-shelf flows clearly just upon the single observation data. Thus, we will give some discussion based on theory and QG potential vorticity equation.

\section{a. Topography-trapped waves}

Topography-trapped waves that maybe occur accompanied by a mesoscale eddy (Oey and Lee 2002; Shu et al. 2016) can also trigger the cross-shelf flow, and then we should demonstrate whether this 10-130-day bandpassed velocity can behave as a topography-trapped wave. 


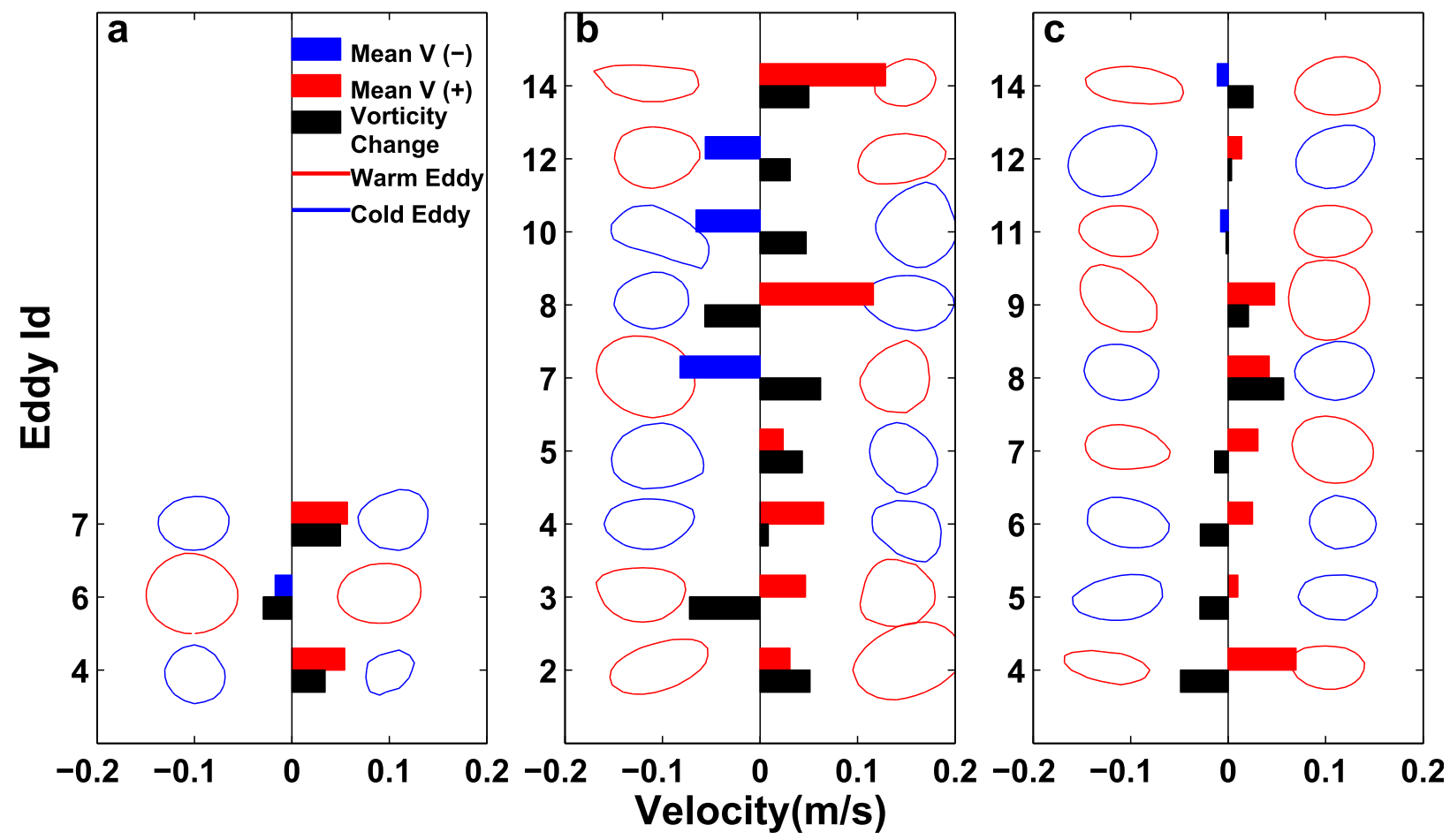

FIG. 8. Mean shape of each mesoscale eddy (contour), net cross-shelf flow (red or blue bar, positive indicates onshore), and value of the relative vorticity changes (black bar) from station (a) A1, (b) A2, and (c) A3. The contour on the left (right) side indicates the mean mesoscale eddy shape when its center is west (east) of the station. The eddy ID numbers are as in Fig. 2.

Topography-trapped waves are plane transverse waves, and their wavenumber vector is perpendicular to the principal axis of the current velocities (Thompson 1977). Thus, we calculated the variance ellipses for the 10-130-day bandpassed velocities from each station (Fig. 13). Dropping planetary beta effect in slope area, topography-trapped wave dispersion relation can be simplified as $\omega=N|\nabla h| \sin (\theta)$, where $\omega$ is frequency, $\nabla h$ is water depth gradient, $N$ is the Brunt-Väisälä frequency, and $\theta$ is the clockwise angle that the wavenumber vector makes with the direction of topography gradient (Oey and Lee 2002). In the NSCS continental shelf region, $N$ is $\sim 1.0 \times 10^{-3} \mathrm{~s}^{-1}$, and $\omega \sim\left[5.59 \times 10^{-7} \mathrm{~s}^{-1}, 7.27 \times 10^{-6} \mathrm{~s}^{-1}\right]$ (i.e., 10-130 day), and then the $\theta$ can be estimated used the water depth gradient at each station (green domain in Fig. 13). For a topography-trapped wave, the short axis of variance ellipse should be within the green domain, and then the topography-trapped wave dispersion relation can be satisfied. However, all the variance ellipse axes locate outside these domains, which demonstrates that these 10-130-day bandpassed signal does not follow topography-trapped wave.

\section{b. Cross-shelf flow in the barotropic QG model}

It is simple without loss of generality to use the barotropic QG potential vorticity equation to discuss the cross-shelf flow induced by the mesoscale eddy:

$$
\frac{\partial q}{\partial t}+J(\varphi, q)-\frac{f}{H} J(\varphi, H)=0
$$

where $q=\nabla^{2} \varphi-F^{2} \varphi, F^{2}=f^{2} /(g H), f$ is the Coriolis parameter, $H$ is water depth, $g$ is gravity acceleration, $\varphi$ is streamfunction, and $J(A, B)=A_{x} B_{y}-A_{y} B_{x}$. The velocity $\mathbf{u}=(u, v)=\left(-\varphi_{y}, \varphi_{x}\right)$. The planetary beta effect has been omitted.

Easily, we can get $J(\varphi, H)=\varphi_{x} H_{y}-\varphi_{y} H_{x}=\mathbf{u} \cdot \nabla H$, and then the cross-shelf flow can be defined as $v_{g}=$ $-(\nabla \mathrm{H} /|\nabla \mathrm{H}|) \cdot \mathbf{u}$, which means onshore is positive.

Then a time-integrated cross-shelf flow can be calculated as

$$
\int_{t 1}^{t 2} v_{g} d t=\underbrace{\left(q_{t 2}-q_{t 1}\right) / \alpha}_{Q}+\underbrace{\left(\int_{t 1}^{t 2} J(\varphi, q) d t\right) / \alpha}_{N t},
$$

where $\alpha=-(f / \mathrm{H})|\nabla \mathrm{H}|$. Term $Q$ indicates the asymmetry or evolution of the mesoscale eddy, and term $N t$ indicates nonlinear effect. The right side of Eq. (2) indicates an accumulation of cross-shelf transport during an eddy propagation, which is controlled by the eddy's evolution $(Q)$ and accumulated nonlinear effect $(N t)$. 

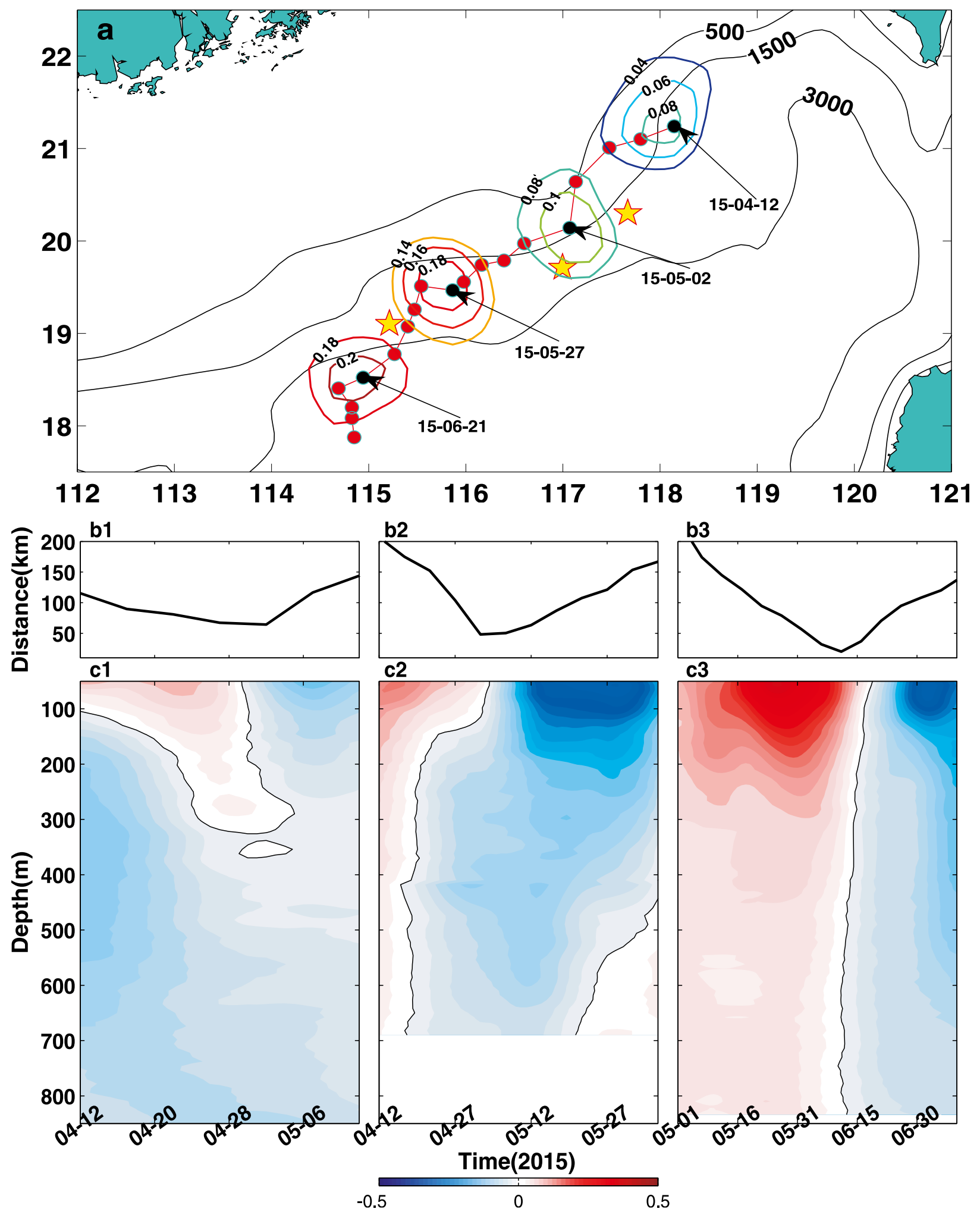

c2

c3
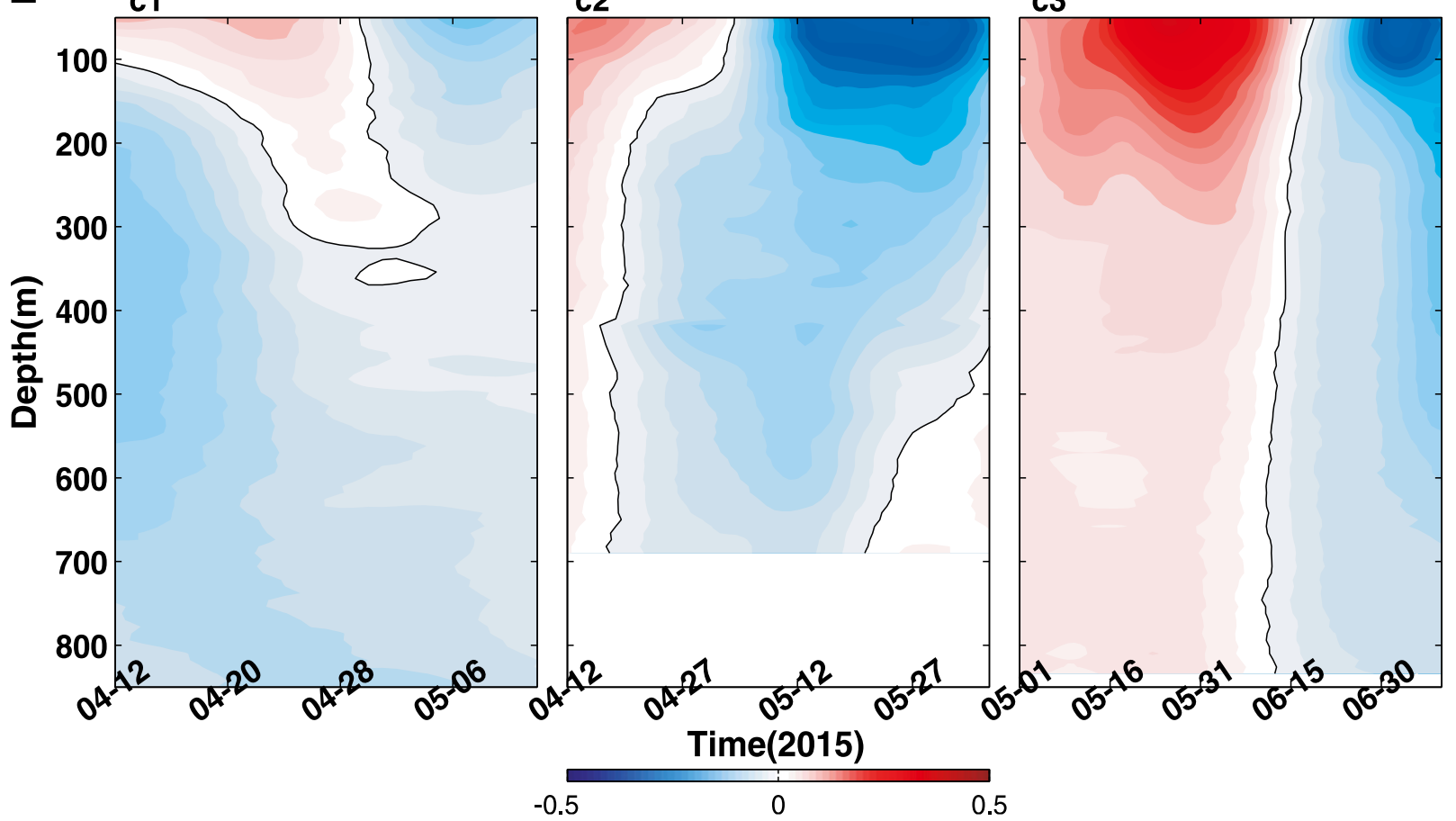

FIG. 9. (a) Path of the mesoscale eddy (case 1) and SSHAs at the corresponding time (color contours). Black contours are isobaths (bathymetry has been smoothed using a five-point filter). The yellow stars indicate mooring stations. The middle panels show distance between the mesoscale eddy center and the mooring station the lower panels show cross-shelf flow profile as the mesoscale eddy propagates past the mooring station from station (b1),(c1) A1; (b2),(c2) A2; and (b3),(c3) A3. 

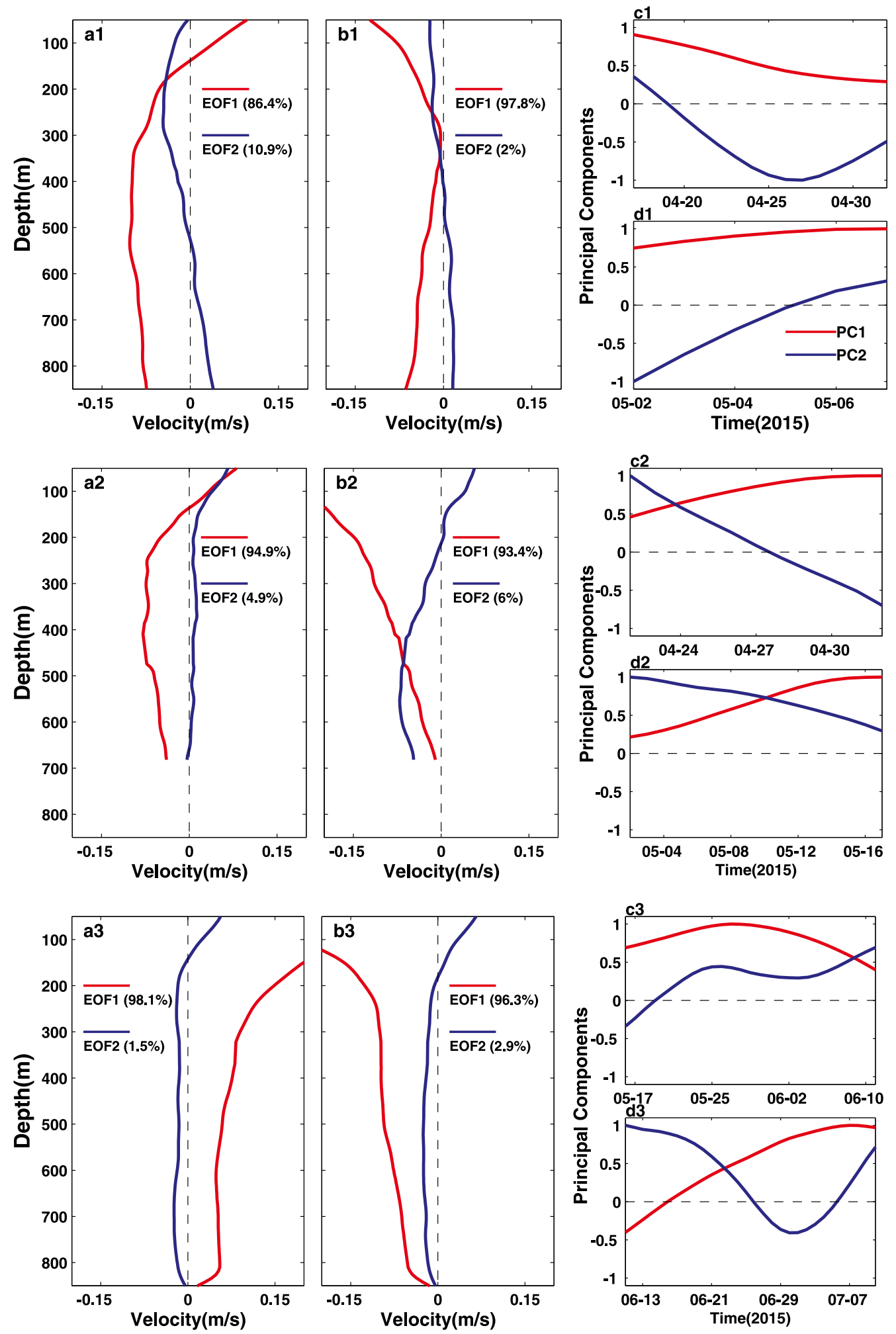

FIG. 10. EOF decomposition of the cross-shelf flow from case 1. (left) The first two EOFs from the period when the mesoscale eddy center is east of the mooring station, (center) the first two EOFs from the period when the mesoscale eddy center is west of the station, and (right) the corresponding principal components from station (top) A1, (middle) A2, and (bottom) A3. 


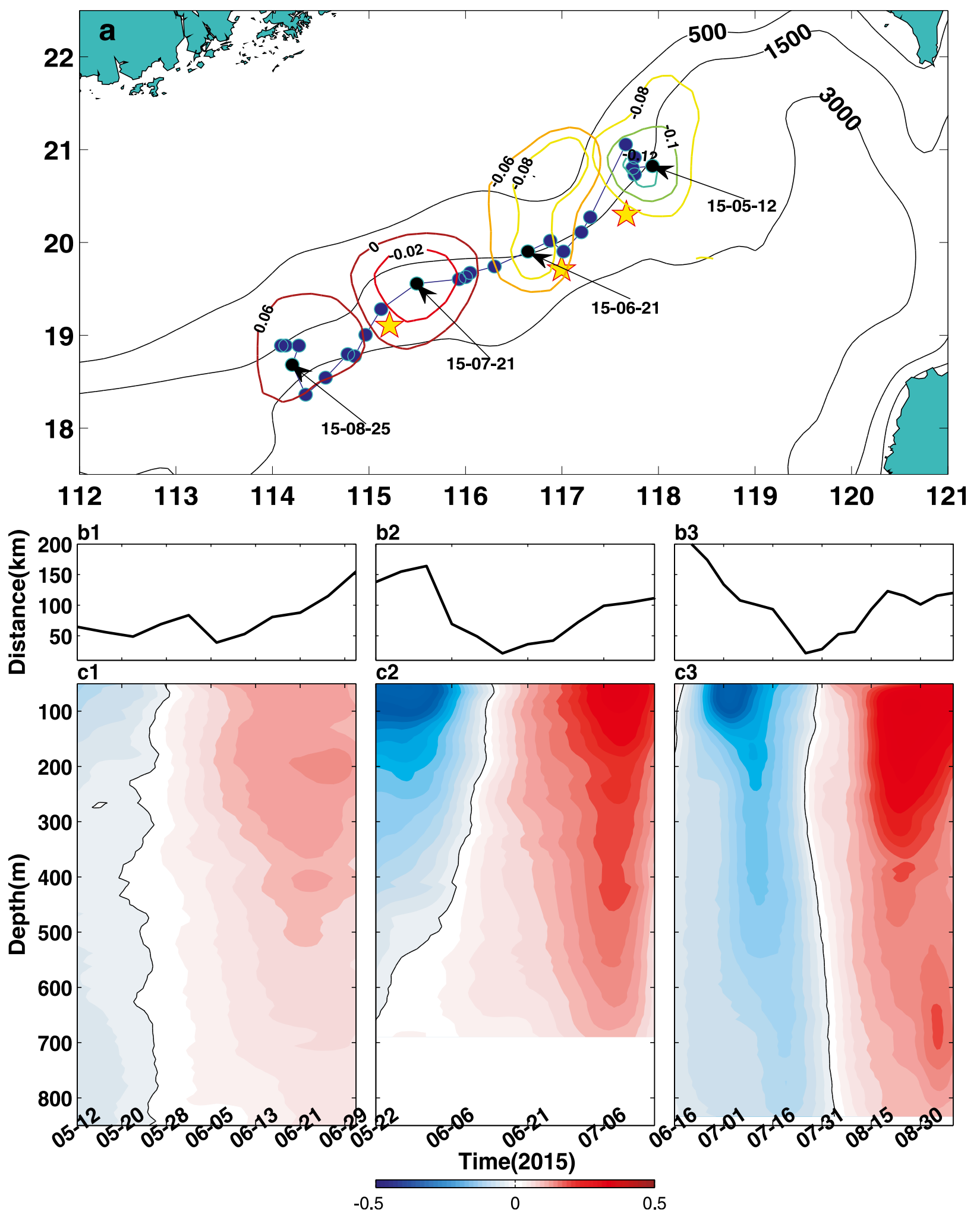

FIG. 11. As in Fig. 9, but for mesoscale eddy case 2. 

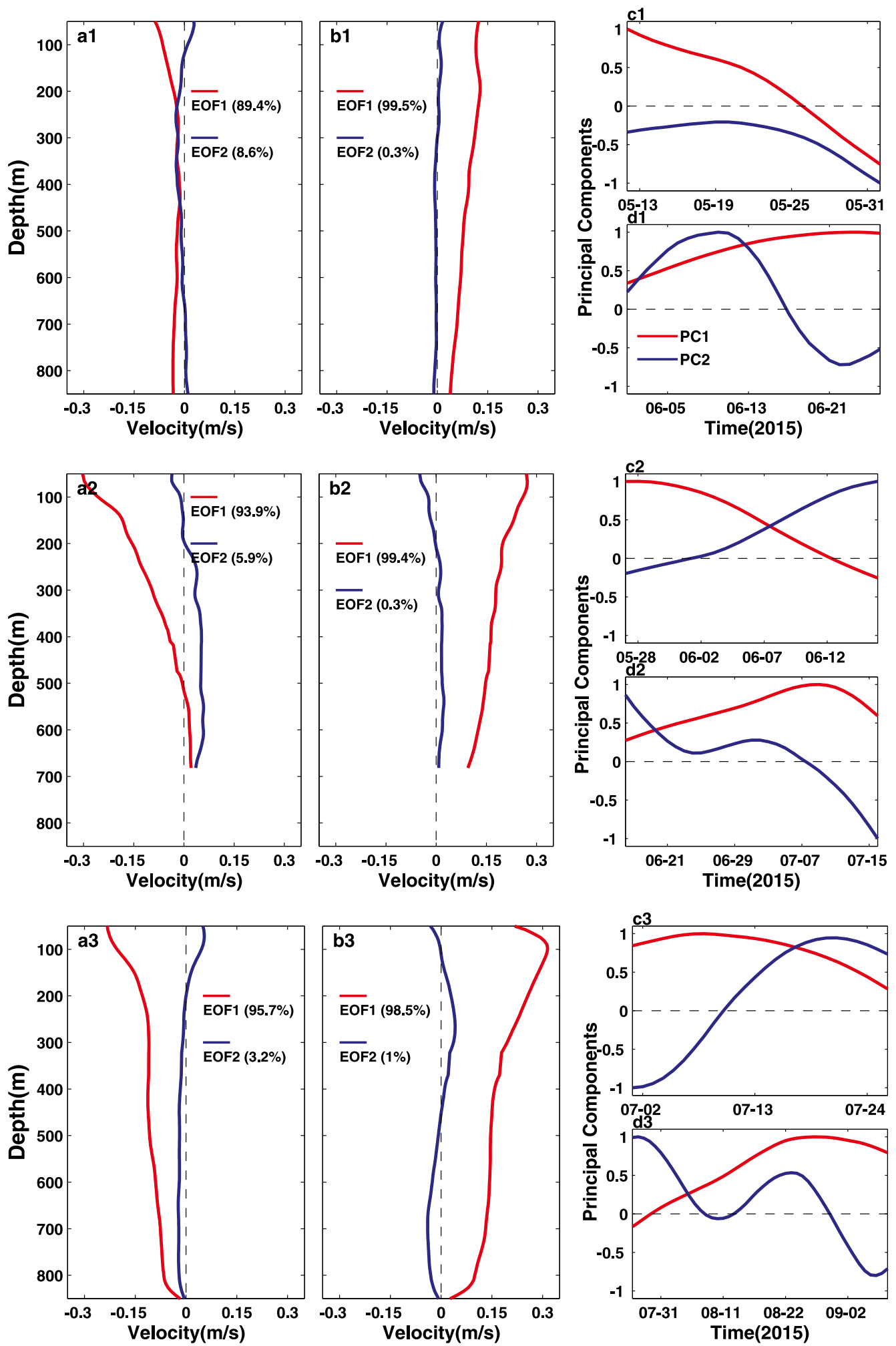

FIG. 12. As in Fig. 10, but for case 2. 
(a)A1: Principal axis at 50m

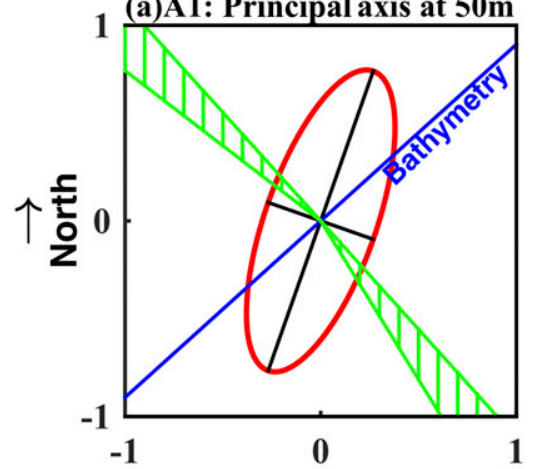

(b)A1: Principal axis at 500m

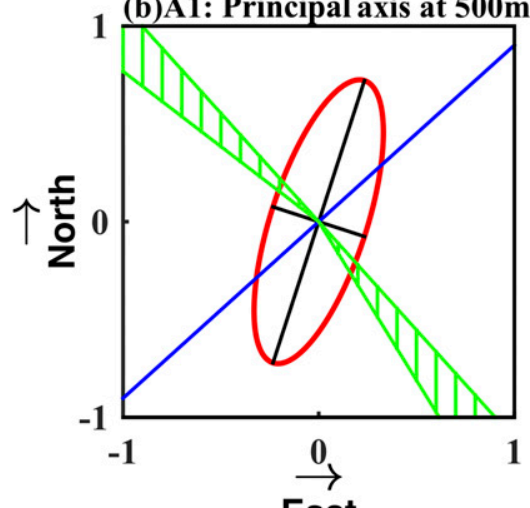

East
(c)A2: Principal axis at 50m

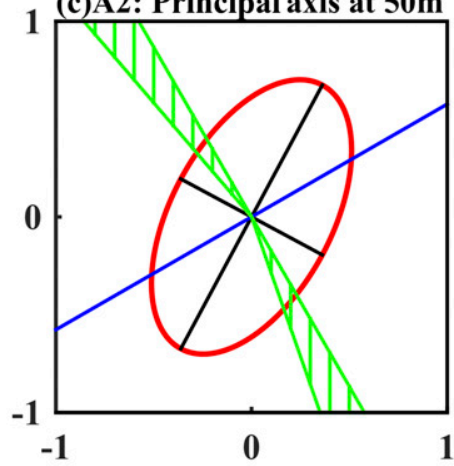

(d)A2: Principal axis at 500m

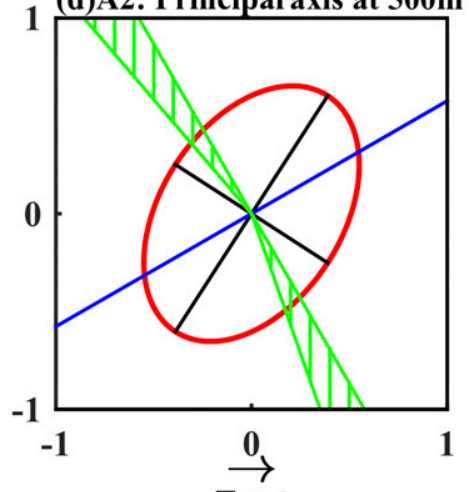

East
(e)A3: Principal axis at 50m

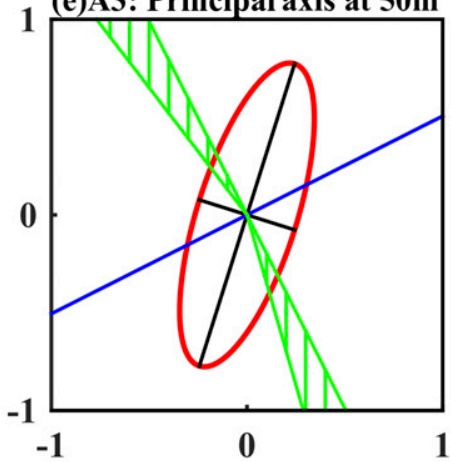

(f)A3: Principal axis at 500m

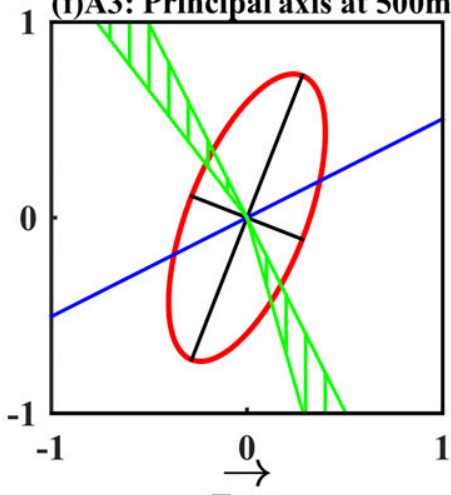

East

FIG. 13. Principal axis variance ellipse of 10-130-day bandpass-filtered velocity at each station. The blue line indicates the bathymetry and green lines indicate topography-trapped wave domain in theory.

Thus, some numerical experiment can be designed. The initial conditions for the numerical studies are of the form $\varphi=A(g / f) e^{-(r / R)^{2}}$ [where $A$ is amplitude of fluctuation, $r=\sqrt{\left(x-x_{o}\right)^{2}+\left(y-y_{o}\right)^{2}}$ is the radial coordinate, $\left(x_{o}, y_{o}\right)$ is the initial location of vortex center, and $R$ is radius of mesoscale eddy]. Only the meridional slope has been considered in this paper. In the control run, all the parameters used in the numerical calculation are listed in Table 2. We focus on the nonlinear effect and bottom slope, and the nonlinear term times 2 in exp2 (i.e., $N t=2$ ), slopes times 0.5 in $\exp 3$ (i.e., $H t=0.5$ ), respectively. There are similar results of cold and warm eddies just with opposite meridional propagation direction, and only a cold eddy example has been given in this paper.

The transport should be zero, when it is integrated between two simultaneous streamfunction lines with the same value. We select a fixed site with initial streamfunction of -3000 locating northwest to the eddy center (Fig. 14) and define the period when it encounters the other side of this streamfunction line as the eddy influence period (i.e., day $=22,21$, and 42 for control, exp1, and exp2, respectively). Using this period, the time has been standardized, and day $=1$ indicates that the site encounters the other side of the selected streamfunction line (Figs. 14b,d,f).

In all experiments, the shape of eddy will deform because of the dispersion characteristics (Flierl 1977). The phase of the mesoscale eddy propagates westward, but the energy propagation lags or opposes the phase speed. The western part of the eddy then becomes loose and the eastern part is enhanced. Because of the dispersion, the

TABLE 2. List of parameters used in quasigeostrophic potential vorticity equations.

\begin{tabular}{lcc}
\hline Parameter & One layer & Two layers \\
\hline$f$ & $5 \times 10^{-5} \mathrm{~s}^{-1}$ & $5 \times 10^{-5} \mathrm{~s}^{-1}$ \\
$\beta$ & - & $2.1 \times 10^{-11} \mathrm{~m}^{-1} \mathrm{~s}^{-1}$ \\
Slope $(\nabla H)$ & -0.002 & -0.002 \\
$H$ & $1000 \mathrm{~m}$ & - \\
$H_{1}$ & - & $200 \mathrm{~m}$ \\
$H_{2}$ & - & $2000 \mathrm{~m}$ \\
$g$ & $9.8 \mathrm{~m} \mathrm{~s}^{-2}$ & - \\
$g^{\prime}$ & - & $0.02 \mathrm{~m} \mathrm{~s}^{-2}$ \\
$A$ & $0.05 \mathrm{~m}$ & $0.05 \mathrm{~m}$ \\
$R$ & $50 \mathrm{~km}$ & $50 \mathrm{~km}$ \\
\hline
\end{tabular}


(a) $\mathrm{Day}=0.5, \mathrm{Nt}=1.0, \mathrm{Ht}=1.0$

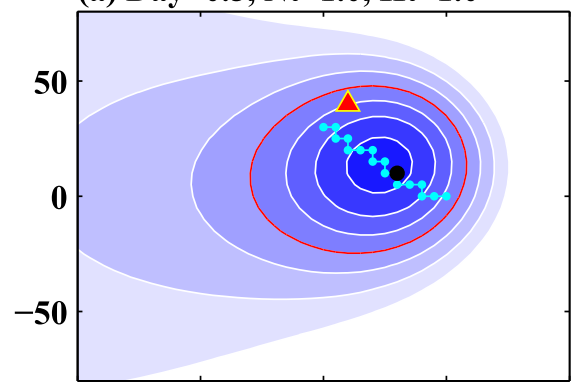

(c) Day $=0.5, \mathrm{Nt}=2.0, \mathrm{Ht}=1.0$

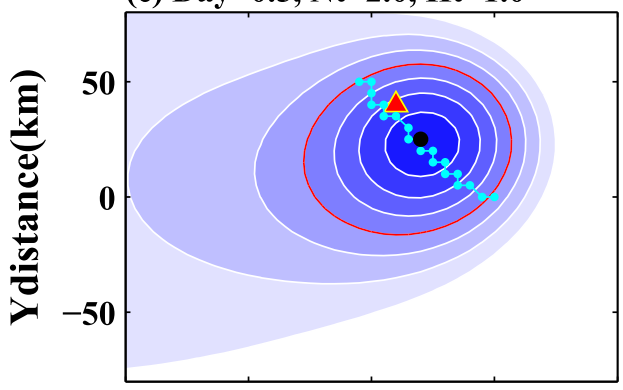

(e) $\mathrm{Day}=0.5, \mathrm{Nt}=1.0, \mathrm{Ht}=0.5$

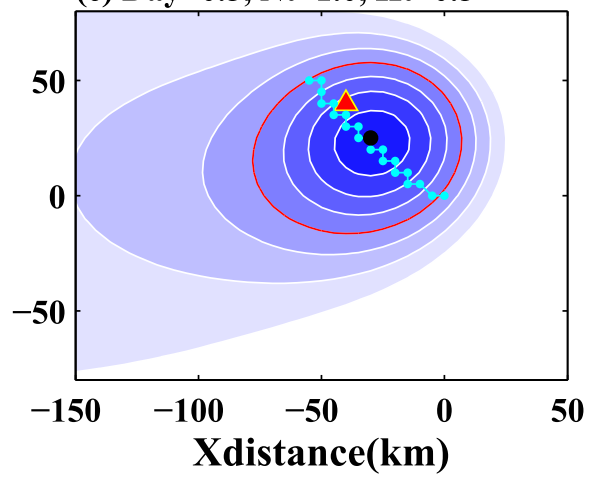

(b) $\mathrm{Day}=1.0, \mathrm{Nt}=1.0, \mathrm{Ht}=1.0$

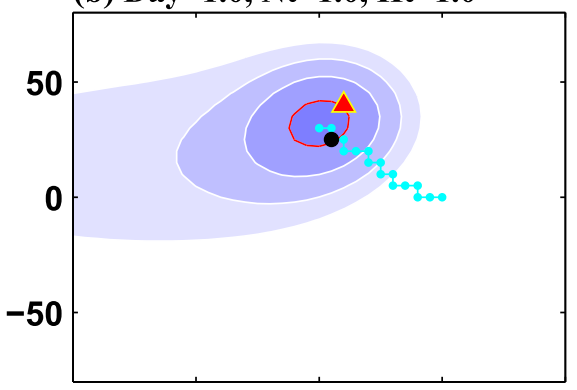

(d) $\mathrm{Day}=1.0, \mathrm{Nt}=\mathbf{2 . 0}, \mathrm{Ht}=1.0$

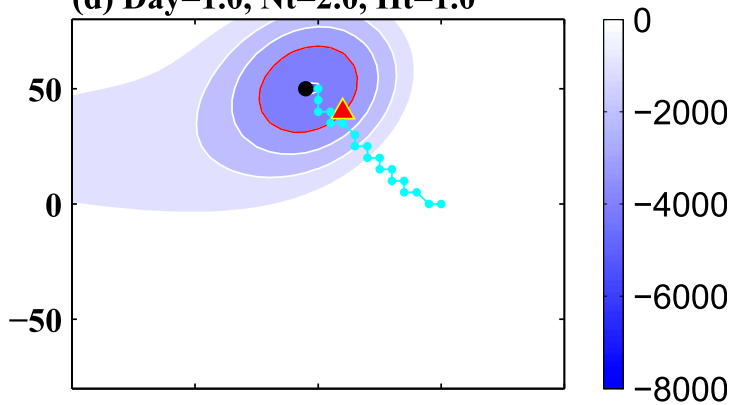

(f) $\mathrm{Day}=1.0, \mathrm{Nt}=1.0, \mathrm{Ht}=0.5$

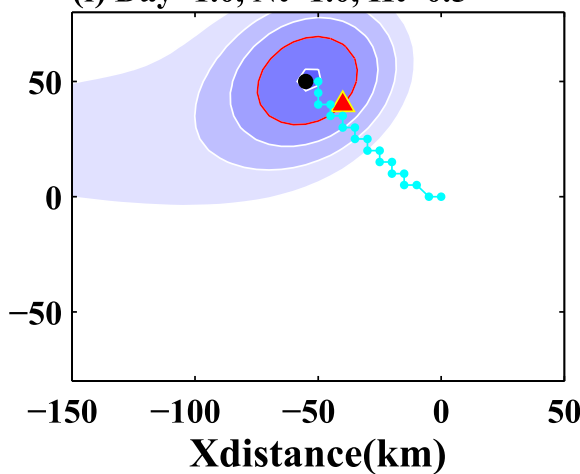

FIG. 14. Distribution of streamfunction calculated from Eq. (1) for (a),(b) the control experiment; (c),(d) the experiment with 2 times nonlinear effect; and (e),(f) the experiment with half bottom slope for (left) streamfunction at day 0.5 and (right) streamfunction at day 1 . The cyan dots are mesoscale eddy centers, the red contour is streamfunction of -3000 , and the red triangle is the selected station to be analyzed.

eddy still dissipates, although there is no friction term in the QG equation. Comparing the three experiments, it can be found that larger nonlinear effect (or smaller slope) can suppress the dispersion (Fig. 14).

The streamfunction and each term of Eq. (2) at the selected site have been shown in Fig. 15. Net cross-shelf flow occurs in all experiments after an eddy influence period (Fig. 15b), and the cross-shelf flow is mainly induced by eddy evolution (i.e., term $Q$ ), suppressed by the nonlinear effect (Fig. 15c). When nonlinear effect is increased (i.e., exp2), the net cross-shelf flow will be reduced slightly. However, net cross-shelf flow will be significantly increased when the slope is reduced (i.e., exp3) due to potential vorticity conservation. Large (small) topography slope demands small (large) crossshelf flow to balance the same vorticity evolution (i.e., $Q$ ), and then large slope suppresses net cross-shelf flow.

\section{c. Vertical mode transformation in the two-layer QG model}

It is convenient to discuss the eddy-induced crossshelf flow using a barotropic QG model that involves the main dynamics process associated with the vertical integrated cross-shelf flow. To discuss the vertical mode transformation during eddy propagation, the barotropic QG model should be expanded to a two-layer QG model without loss of the main vertical integrated movement characters: 

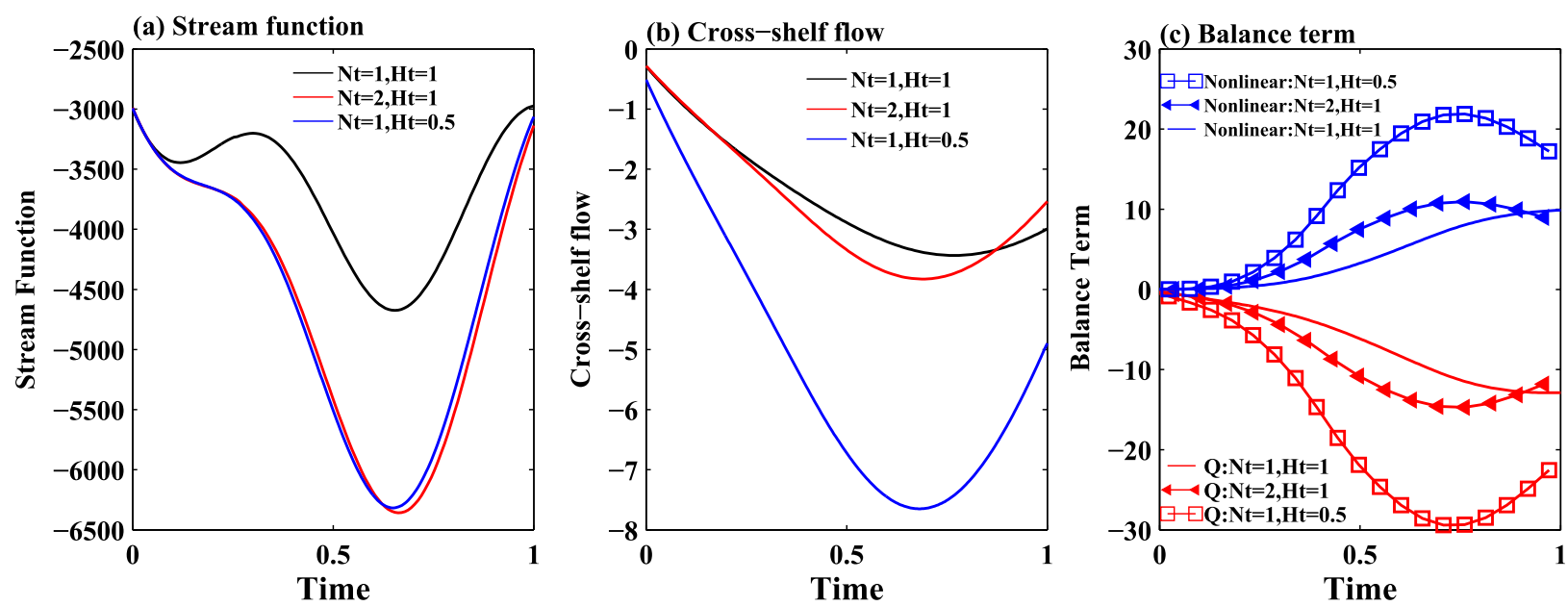

FIG. 15. Time series of (a) streamfunction, (b) time integrated cross-shelf flow [left term in Eq. (2)], and (c) evolution of the mesoscale eddy $(Q)$ and nonlinear effect $(N t)$. All the values are from the selected station marked in Fig. 14.

$$
\begin{aligned}
\frac{\partial q_{1}}{\partial t}+J\left(\varphi_{1}, q_{1}\right)+\beta \frac{\partial \varphi_{1}}{\partial x} & =0, \quad \text { and } \\
\frac{\partial q_{2}}{\partial t}+J\left(\varphi_{2}, q_{2}\right)+\beta \frac{\partial \varphi_{2}}{\partial x}-\frac{f}{H_{2}} J\left(\varphi_{2}, H\right) & =0,
\end{aligned}
$$

where $q_{1}=\nabla^{2} \varphi_{1}-F_{1}^{2}\left(\varphi_{1}-\varphi_{2}\right)$ and $q_{2}=\nabla^{2} \varphi_{2}+$ $F_{2}^{2}\left(\varphi_{1}-\varphi_{2}\right)$ are relative potential vorticity, $F_{1}^{2}=f^{2} /\left(g^{\prime} H_{1}\right)$, $F_{2}^{2}=f^{2} /\left(g^{\prime} H_{2}\right),\left(H_{1}, H_{2}\right)$ are the upper and lower layer averaged thickness, $g$ ' is reduced gravity acceleration, and $\beta$ is the planetary beta effect.

Following McWilliams and Flierl (1979), the barotropic $\left(p_{t}\right)$ and first baroclinic $\left(p_{c}\right)$ modes can be defined as

$$
\begin{aligned}
& \left(\delta^{1 / 2}+\delta^{-1 / 2}\right) p_{t}=\delta^{1 / 2} \varphi_{1}+\delta^{-1 / 2} \varphi_{2}, \quad \text { and } \\
& \left(\delta^{1 / 2}+\delta^{-1 / 2}\right) p_{c}=\varphi_{1}-\varphi_{2},
\end{aligned}
$$

where $\delta=H_{1} / H_{2}$.

The initial condition for $\varphi_{1}$ is the same as that in the barotropic model, and $\varphi_{2}=0.5 \varphi_{1}$, in which both barotropic and baroclinic mode can be involved. Four experiments have been designed and the details are listed in Table 3.

At the first few days, barotropic mode propagates quite fast and leaves the baroclinic mode behind (Fig. 16a) due to the topography planetary beta effect being far bigger than the planetary beta effect. However, after a longer time, the barotropic mode will be reconstructed in the baroclinic mode area, as the accumulation of barotropic mode energy propagates eastward (Fig. 16b). Nonlinear effect gives a meridional propagation speed and suppresses the eddy dissipation (Figs. 16c,d). When topography effect is removed, the separation of barotropic and baroclinic mode develops quite slowly, for both of them are controlled by planetary beta effect (Figs. 16e,f). Enhanced topography effect accelerates the separation and the reconstruction (Figs. 16g,h).

Further, the ratio between barotropic and baroclinic mode at the baroclinic mode center is investigated (Fig. 17). In the first 5 days, the barotropic mode reduces dramatically except for the experiment without topography slope, and then increases gradually. Nonlinear effect gives almost no influence on this ratio development; however, the topography beta effect dominates this process. Bigger topography beta effect gives a faster and stronger barotropic mode reconstruction.

\section{Conclusions}

Mesoscale eddies are highly active ocean phenomena with a significant influence on ocean movement and dynamics. Much effort has been expended in investigating their features and driving mechanisms. In this study, three long-period moorings have been analyzed and the cross-shelf flow induced by mesoscale eddies has been investigated. Several conclusions can be drawn.

A mesoscale eddy can induce different cross-shelf flow in different positions. On the northward rising topography in the NSCS, a warm eddy can induce onshore

TABLE 3. Details of two-layer model experiments.

\begin{tabular}{ccc}
\hline \hline Name & Slope $(\nabla H)$ & Nonlinear $(N t)$ \\
\hline Exp1 & -0.002 & Yes \\
Exp2 & -0.002 & No \\
Exp3 & 0 & Yes \\
Exp4 & -0.004 & Yes
\end{tabular}



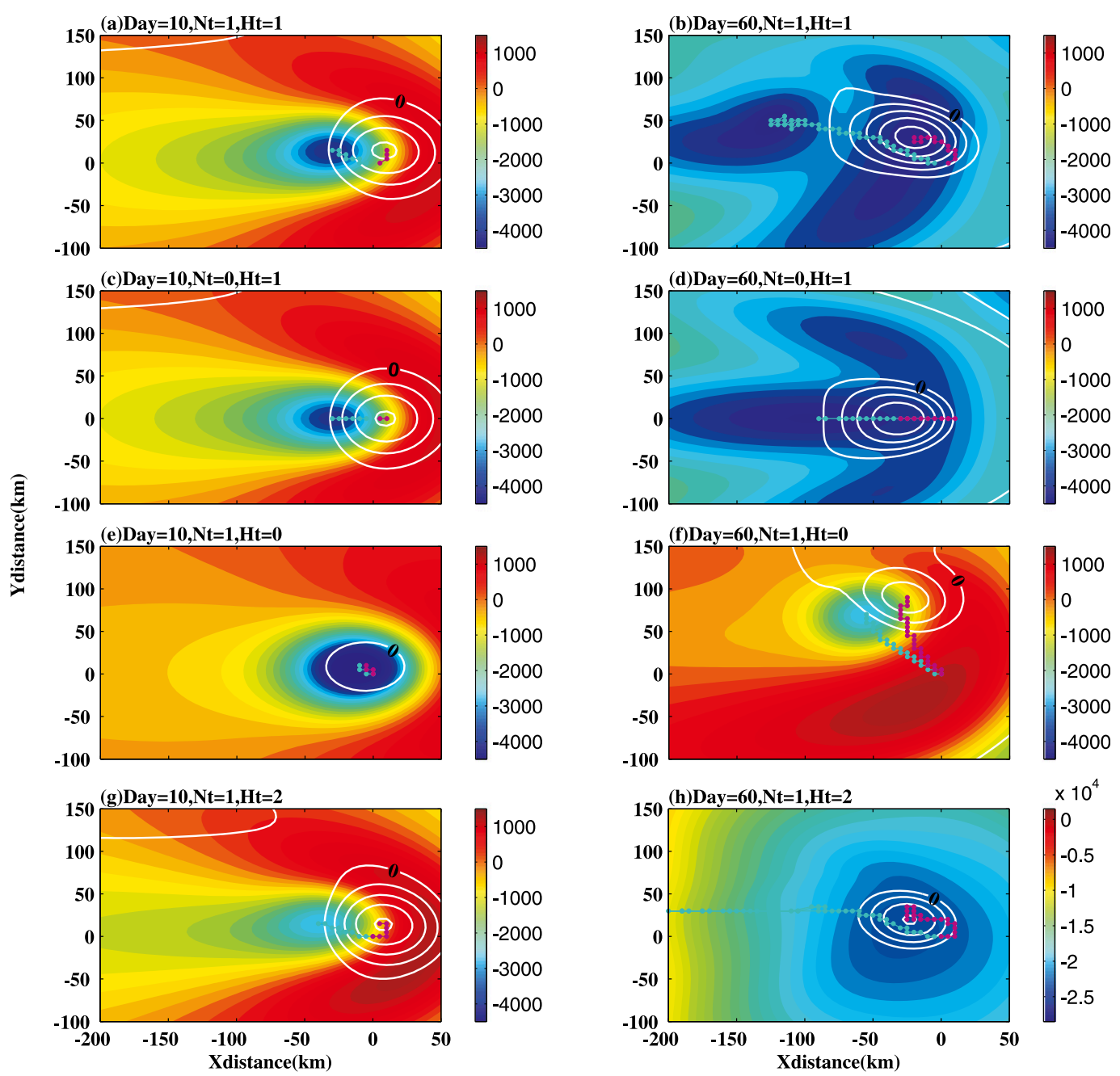

FIG. 16. Distribution of streamfunction from two-layer QG potential vorticity equation (shading indicates barotropic mode; contour indicates baroclinic mode with interval of -200) for (a),(b) the control experiment; (c),(d) the experiment without nonlinear term; (e),(f) the experiment without topography slope; and (g),(h) the experiment with double topography slope compared with control experiment for (left) results at day 10 and (right) results at day 60. Cyan dots are centers of barotropic mode, and purple dots are centers of baroclinic mode.

cross-shelf flow in the first and fourth quadrants, but offshore in the second and third quadrants. A cold eddy has the opposite effect. This is consistent with the horizontal structure of eddies. Under geostrophic balance, the anticlockwise (clockwise) rotation of a warm (cold) eddy can induce upslope (downslope) movement in its western part and downslope (upslope) in its eastern part.

Net cross-shelf flow will be induced by the eddy's asymmetric structure and evolution. First, none of the eddies considered had a regular circular shape, so the eddy velocity field is also significantly asymmetric. Different cross-shelf flows occurred in its different parts, so that net cross-shelf flow is induced by the horizontal asymmetric structure as the eddy propagates past. Second, the vertical structure is also asymmetric. Different vertical modes can be found as an eddy moved past the mooring stations, which also induces net cross-shelf flow. Third, mesoscale eddies always evolve and contribute to the net cross-shelf flow. Ensemble estimation and case studies show that the eddy shape changes continually and high baroclinic modes transform to lower modes during its westward propagation.

Based on the quasigeostrophic potential vorticity equation, it is confirmed that the net cross-shelf flow is mainly induced by the eddy evolution and suppressed by nonlinear effect. When topography slope increases, the net cross-shelf flow will be reduced, constrained by the potential vorticity conservation. For the different propagation speed of barotropic and baroclinic modes, barotropic mode propagates quite fast and leaves the baroclinic mode behind; however, 


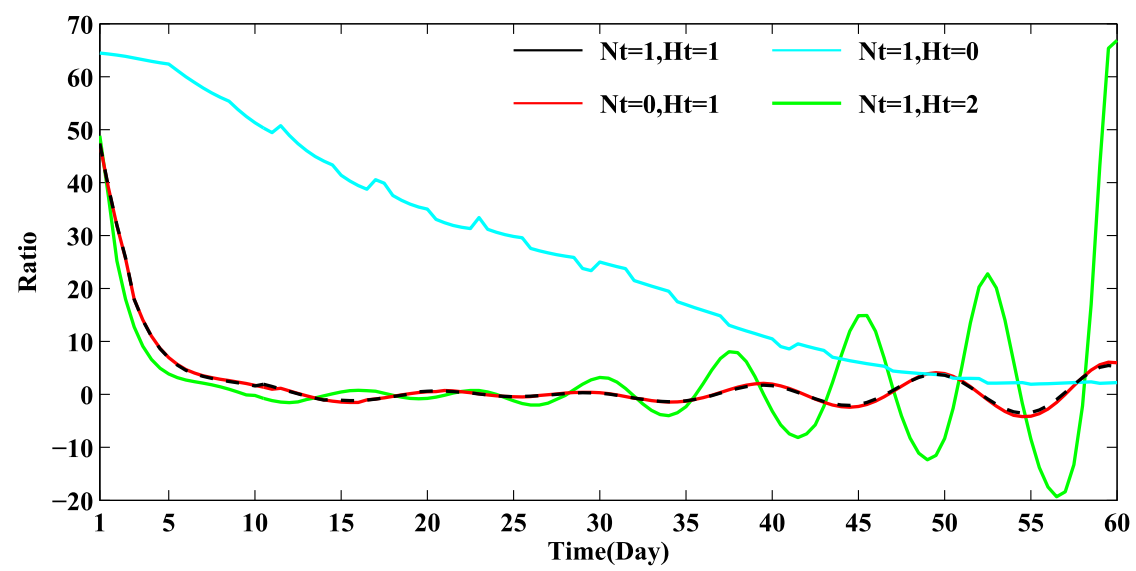

FIG. 17. Time series of ratio between barotropic mode and baroclinic mode at the center of baroclinic mode.

barotropic mode will restructure at the baroclinic mode area after separating from the baroclinic mode due to dispersion characteristics of the mesoscale eddy, which will be enhanced by topography slope.

This paper has described eddy-induced cross-shelf flow and has given some useful insight into eddy evolution in the NSCS to help understand eddy features. However, there are still many issues that need to be investigated, such as the details of flow-eddy interaction and the effect of topography on eddy evolution. We will start on model analysis in future work, based on the results of the present investigation.

Acknowledgments. The SSHA data for this paper are available at_https://www.aviso.altimetry.fr. The datasets used are nrt_global_merged_madt_h and nrt_global_merged_msla_h. The processed mooring data used to construct figures in this work are also available, and these data can be obtained from the corresponding author, Dongxiao Wang (dxwang@scsio.ac.cn). This work was supported by the Frontier Science research project of Chinese Academy of Sciences (Grant QYZDJSSW-DQC022) and the National Natural Science Foundation of China (Grants, 41776026, 41521005, 41406038, 41776025, 41476012, 41576012, 41776036, 41676012). L.Z. is also sponsored by the Pearl River S\&T Nova Program of Guangzhou and the Open Project Program of State Key Laboratory of Tropical Oceanography (LTOZZ1601).

\section{REFERENCES}

Chen, G. X., Y. J. Hou, and X. Q. Chu, 2011: Mesoscale eddies in the South China Sea: Mean properties, spatiotemporal variability, and impact on thermohaline structure. J. Geophys. Res., 116, C06018, https://doi.org/10.1029/2011JD016244.
J. Gan, Q. Xie, X. Chu, D. Wang, and Y. Hou, 2012: Eddy heat and salt transports in the South China Sea and their seasonal modulations. J. Geophys. Res., 117, C05021, https:// doi.org/10.1029/2011JC007724.

Chow, C. H., J. H. Hu, R. L. Centurioni, and P. P. Niiler, 2008: Mesoscale Dongsha cyclonic eddy in the northern South China Sea by drifter and satellite observations. J. Geophys. Res., 113, C04018, https://doi.org/10.1029/2007JC004542.

Chu, P. C., C. W. Fan, C. J. Lozano, and J. L. Kerling, 1998: An airborne expendable bathythermograph survey of the South China Sea, May 1995. J. Geophys. Res., 103, $21637-21652$, https://doi.org/10.1029/98JC02096.

Chu, X. Q., H. J. Xue, Y. Q. Qi, G. X. Chen, Q. W. Mao, D. X. Wang, and F. Chai, 2014: An exceptional anticyclonic eddy in the South China Sea in 2010. J. Geophys. Res. Oceans, 119, 881-897, https://doi.org/10.1002/2013JC009314.

Dong, C., X. Lin, Y. Liu, F. Nencioli, Y. Chao, Y. Guan, T. Dickey, and J. McWilliams, 2012: Three-dimensional eddy analysis in the Southern California Bight. J. Geophys. Res., 117, C00H14, https://doi.org/10.1029/2011JC007354.

_ J. C. McWilliams, Y. Liu, and D. Chen, 2014: Global heat and salt transports by eddy movement. Nat. Commun., 5, 3294, https://doi.org/10.1038/ncomms4294.

Flierl, G., 1977: The application of linear quasi-geostrophic dynamics to Gulf Stream rings. J. Phys. Oceanogr., 7, 365-379, https://doi.org/10.1175/1520-0485(1977)007<0365:TAOLQD> 2.0.CO;2.

Hu, J., H. Kawamura, H. Hong, and Y. Qi, 2000: A review on the currents in the South China Sea: Seasonal circulation, South China Sea warm current and Kuroshio intrusion. J. Oceanogr., 56, 607-624, https://doi.org/10.1023/A:1011117531252.

Huang, X. R., Q. Wang, W. D. Zhou, and S. Q. Zhou, 2016: A study of the cross-shelf flow around Dongsha Island in the South China Sea in winter using a diagnostic model (in Chinese with English abstract). J. Trop. Oceanogr., 35 (6), 1-9.

,,-- and,- 2017 : Model diagnostic analysis of cross-shelf flow in the northern South China Sea (in Chinese with English abstract). Chin. Sci. Bull., 62, 1059-1070, https:// doi.org/10.1360/N972016-00570.

Jia, Y., and Q. Liu, 2004: Eddy shedding from the Kuroshio bend at Luzon Strait. J. Oceanogr., 60, 1063-1069, https://doi.org/ 10.1007/s10872-005-0014-6. 
Li, L., W. D. Nowlin, and J. L. Su, 1998: Anticyclonic rings from the Kuroshio in the South China Sea. Deep-Sea Res. I, 45, 1469-1482, https://doi.org/10.1016/S0967-0637(98) 00026-0.

Li, Y., L. Li, M. Lin, and W. Cai, 2002: Observation of mesoscale eddy fields in the sea southwest of Taiwan by TOPEX/ Poseidon altimeter data (in Chinese with English abstract). Acta Oceanol. Sin., 24, 163-170.

Liu, Y., C. Dong, Y. Guan, D. Chen, J. McWilliams, and F. Nencioli, 2012: Eddy analysis in a zonal band in the North Pacific Ocean. Deep-Sea Res. I, 68, 54-67, https://doi.org/ 10.1016/j.dsr.2012.06.001.

Marks, K. M., and W. H. F. Smith, 2006: An evaluation of publicity available global bathymetry grids. Mar. Geophys. Res., 27, 19-34, https://doi.org/10.1007/s11001-005-2095-4.

McWilliams, J. C., and G. R. Flierl, 1979: On the evolution of isolated, nonlinear vortices. J. Phys. Oceanogr., 9, 1155-1182, https://doi.org/10.1175/1520-0485(1979)009<1155: OTEOIN $>2.0 . \mathrm{CO} ; 2$.

Mizobata, K., J. Wang, and S.-I. Saitoh, 2006: Eddy-induced crossslope exchange maintaining summer high productivity of the Bering Sea shelf break. J. Geophys. Res., 111, C10017, https:// doi.org/10.1029/2005JC003335.

Nan, F., H. Xue, X. Xiu, F. Chai, M. Shi, and P. Guo, 2011: Oceanic eddy formation and propagation southwest of Taiwan. J. Geophys. Res., 116, C12045, https://doi.org/10.1029/ 2011JC007386.

Nencioli, F., C. M. Dong, T. Dickey, L. Washburn, and J. C. McWilliams, 2010: A vector geometry-based eddy detection algorithm and its application to a high-resolution numerical model product and high-frequency radar surface velocities in the Southern California Bight. J. Atmos. Oceanic Technol., 27, 564-579, https://doi.org/10.1175/2009JTECHO725.1.

Nof, D., Y. L. Jia, E. Chassignet, and A. Bozec, 2011: Fast wind-induced migration of leddies in the South China Sea. J. Phys. Oceanogr., 41, 1683-1693, https://doi.org/10.1175/ 2011JPO4530.1.

Oey, L. Y., and H. C. Lee, 2002: Deep eddy energy and topographic Rossby waves in the Gulf of Mexico. J. Phys. Oceanogr., 32, 3499-3527, https://doi.org/10.1175/1520-0485(2002)032<3499: DEEATR $>2.0 . \mathrm{CO} ; 2$.

Peliz, Á., A. M. P. Santos, P. B. Oliveira, and J. Dubert, 2004: Extreme cross-shelf transport induced by eddy interactions southwest of Iberia in winter 2001. Geophys. Res. Lett., 31, L08301, https://doi.org/10.1029/2004GL019618.

Qiu, B., and S. Chen, 2005: Eddy-induced heat transport in the subtropical North Pacific from Argo, TMI and altimetry measurements. J. Phys. Oceanogr., 35, 458-473, https:// doi.org/10.1175/JPO2696.1.

Qu, T., 2000: Upper-layer circulation in the South China Sea. J. Phys. Oceanogr., 30, 1450-1460, https://doi.org/10.1175/ 1520-0485(2000)030<1450:ULCITS $>2.0$.CO;2.

Shu, Y. Q., and Coauthors, 2016: Persistent and energetic bottomtrapped topographic Rossby waves observed in the southern South China Sea. Sci. Rep., 6, 24338, https://doi.org/10.1038/ srep24338.

Smith, D., 1986: A numerical study of Loop Current eddy interaction with topography in the western Gulf of Mexico. J. Phys. Oceanogr., 16, 1260-1272, https://doi.org/10.1175/ 1520-0485(1986)016<1260:ANSOLC>2.0.CO;2.

Stammer, D., 1998: On eddy characteristics, eddy transports, and mean flow properties. J. Phys. Oceanogr., 28, 727-739, https:// doi.org/10.1175/1520-0485(1998)028<0727:OECETA >2.0.CO;2.
Su, J., J. Lu, Y. Hou, G. Fang, Z. Wei, and B. Yin, 2002: Analysis of satellite-tracked drifting buoys in the South China Sea (in Chinese with English abstract). Oceanol. Limnol. Sin., 33, 121-127.

Sutyrin, G. G., G. D. Rowe, L. M. Rothstein, and I. Ginis, 2003: Baroclinic eddy interactions with continental slopes and shelves. J. Phys. Oceanogr., 33, 283-291, https://doi.org/10.1175/ 1520-0485(2003)033<0283:BEIWCS $>2.0$. CO;2.

Thompson, R. O. R. Y., 1977: Observation of Rossby waves near site D. Prog. Oceanogr., 7, 135-162, https://doi.org/10.1016/ 0079-6611(77)90003-9.

Wang, D. X., H. Z. Xu, J. Lin, and J. Y. Hu, 2008: Anticyclonic eddies in the northeastern South China Sea during winter 2003/2004. J. Oceanogr., 64, 925-935, https://doi.org/10.1007/ s10872-008-0076-3.

— B. Hong, J. P. Gan, and H. Z. Xu, 2010: Numerical investigation on propulsion of the counter-wind current in the northern South China Sea in winter. Deep-Sea Res. I, 57, 12061221, https://doi.org/10.1016/j.dsr.2010.06.007.

—, Q. Wang, W. Zhou, S. Cai, L. Li, and B. Hong, 2013a: An analysis of the current deflection around Dongsha Islands in the northern South China Sea. J. Geophys. Res. Oceans, 118, 490-501, https://doi.org/10.1029/2012JC008429.

_ , and Coauthors, 2013b: Progress of regional oceanography study associated with western boundary current in the South China Sea. Chin. Sci. Bull., 58, 1205-1215, https://doi.org/ 10.1007/s11434-012-5663-4.

—, Y. Shu, H. Xue, J. Hu, J. Chen, W. Zhuang, T. T. Zu, and J. Xu, 2014: Relative contributions of local wind and topography to the coastal upwelling intensity in the northern South China Sea. J. Geophys. Res. Oceans, 119, 2550-2567, https:// doi.org/10.1002/2013JC009172.

Wang, G., J. Su, and P. C. Chu, 2003: Mesoscale eddies in the South China Sea observed with altimeter data. Geophys. Res. Lett., 30, 2121, https://doi.org/10.1029/2003GL018532.

Wang, L., C. J. Koblinsky, and S. Howden, 2000: Mesoscale variability in the South China Sea from the TOPEX/Poseidon altimetry data. Deep-Sea Res. I, 47, 681-708, https://doi.org/ 10.1016/S0967-0637(99)00068-0.

Wang, Q., Y. X. Wang, W. D. Zhou, D. X. Wang, D. D. Sui, and J. Chen, 2015a: Dynamic of the upper cross isobaths flow on the northern South China Sea in summer. Aquat. Ecosyst. Health Manage., 18, 357-366, https://doi.org/10.1080/ 14634988.2015.1112124.

— , L. Zeng, W. Zhou, Q. Xie, S. Cai, J. Yao, and D. Wang, 2015b: Mesoscale eddies cases study at Xisha waters in the South China Sea in 2009/2010. J. Geophys. Res. Oceans, 120, 517-532, https://doi.org/10.1002/2014JC009814.

Welsh, S., and M. Inoue, 2000: Loop Current rings and the deep circulation in the Gulf of Mexico. J. Geophys. Res., 105, 16 951-16 959, https://doi.org/10.1029/2000JC900054.

Wunsch, C., 1999: Where do ocean eddy heat fluxes matter? J. Geophys. Res., 104, 13 235-13250, https://doi.org/10.1029/1999JC900062.

Xiu, P., F. Chai, L. Shi, H. J. Xue, and Y. Chao, 2010: A census of eddy activities in the South China Sea during 1993-2007. J. Geophys. Res., 115, C03012, https://doi.org/10.1029/2009JC005657.

Xu, X. Z., Z. Qiu, and H. C. Chen, 1982: The general descriptions of the horizontal circulation in the South China Sea (in Chinese with English abstract). Proceedings of the 1980 Symposium on Hydrometeorology of the Chinese Society of Oceanology and Limnology, Science Press, 137-145.

Yang, H. J., and Q. Y. Liu, 2003: Forced Rossby wave in the northern South China Sea. Deep-Sea Res. I, 50, 917-926, https://doi.org/10.1016/S0967-0637(03)00074-8. 
Yang, K., P. Shi, D. Wang, and Y. Qi, 2000: Numerical study about the mesoscale multi-eddy system in the northern South China Sea in winter (in Chinese with English abstract). Acta Oceanol. Sin., 22 (1), 27-34.

Yang, Y., Y. X. Wang, J. P. Sui, W. D. Zhou, and Q. Wang, 2016: Slowdown of the topography trapped wave propagation by the Dongsha Islands in the northern South China Sea. Ocean Dyn., 66, 11-17, https://doi.org/10.1007/s10236-015-0904-0.

Yuan, D., W. Han, and D. Hu, 2006: Surface Kuroshio path in the Luzon Strait area derived from satellite remote sensing data. J. Geophys. Res., 111, C11007, https://doi.org/10.1029/ $2005 \mathrm{JC} 003412$.

,-- , and -2007 : Anti-cyclonic eddies northwest of Luzon in summer-fall observed by satellite altimeters. Geophys. Res. Lett., 34, L13610, https://doi.org/10.1029/2007GL029401.
Zhang, Z., W. Wang, and B. Qiu, 2014: Oceanic mass transport by mesoscale eddies. Science, 345, 322-324, https://doi.org/ 10.1126/science. 1252418 .

_ J. W. Tian, B. Qiu, W. Zhao, P. Chang, D. X. Wu, and X. Q. Wan, 2016: Observed 3D structure, generation, and dissipation of oceanic mesoscale eddies in the South China Sea. Sci. Rep., 6, 24349, https://doi.org/10.1038/srep24349.

Zhuang, W., Y. Du, D. X. Wang, Q. Xie, and S. P. Xie, 2010: Pathways of mesoscale variability in the South China Sea. Chin. J. Oceanol. Limnol., 28, 1055-1067, https://doi.org/ 10.1007/s00343-010-0035-x.

Zu, T. T., D. X. Wang, C. X. Yan, I. Belkin, W. Zhuang, and J. Chen, 2013: Evolution of an anticyclonic eddy southwest of Taiwan. Ocean Dyn., 63, 519-531, https://doi.org/10.1007/ s10236-013-0612-6. 